\title{
Methodology for Shrapnel and Debris Impact and an Assessment for an Experiment Planned for NIF
}

D. C. Eder, M. T. Tobin, O. S. Jones, D. G. Braun, M. J. Shaw, R. E. Tokheim, T. Cooper, B. Lew

September 29, 2000

U.S. Department of Energy

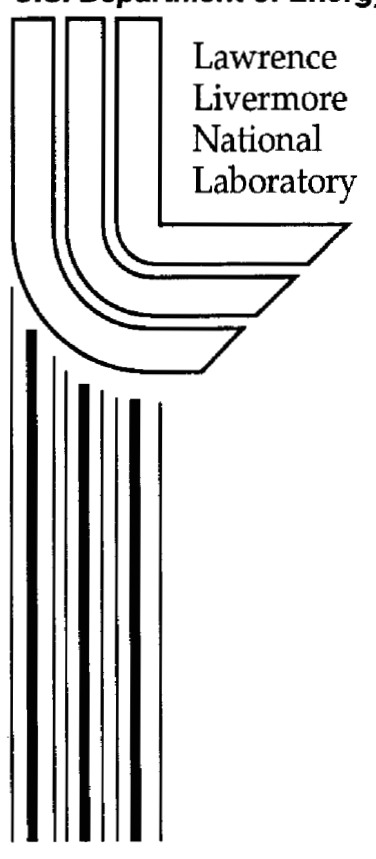




\section{DISCLAIMER}

This document was prepared as an account of work sponsored by an agency of the United States Government. Neither the United States Government nor the University of California nor any of their employees, makes any warranty, express or implied, or assumes any legal liability or responsibility for the accuracy, completeness, or usefulness of any information, apparatus, product, or process disclosed, or represents that its use would not infringe privately owned rights. Reference herein to any specific commercial product, process, or service by trade name, trademark, manufacturer, or otherwise, does not necessarily constitute or imply its endorsement, recommendation, or favoring by the United States Government or the University of California. The views and opinions of authors expressed herein do not necessarily state or reflect those of the United States Government or the University of California, and shall not be used for advertising or product endorsement purposes.

This work was performed under the auspices of the U.S. Department of Energy by the University of California, Lawrence Livermore National Laboratory under Contract No. W-7405-Eng-48.

This report has been reproduced directly from the best available copy.

Available to DOE and DOE contractors from the Office of Scientific and Technical Information

P.O. Box 62, Oak Ridge, TN 37831

Prices available from (423) 576-8401 http://apollo.osti.gov/bridge/

Available to the public from the National Technical Information Service

U.S. Department of Commerce 5285 Port Royal Rd., Springfield, VA 22161 http://www.ntis.gov/

OR

Lawrence Livermore National Laboratory Technical Information Department's Digital Library http://www.llnl.gov/tid/Library.html 


\section{Methodology for Shrapnel and Debris Impact and an Assessment for an Experiment planned for NIF}

D. C. Eder, M.T. Tobin, O. S. Jones, D. G. Braun, and M. J. Shaw Lawrence Livermore National Laboratory

R. E. Tokheim, T. Cooper, and B. Lew Poulter Laboratory, SRI International 


\section{INTRODUCTION}

This report servers two purposes: first, it suggests a detailed methodology for assessing the debris-shield impacts of experiments planned to be conducted on NIF; second, it describes the most thorough examination of an experiment's impacts on NIF done to date. In addition, we comment on what needs exist for further improvements in computational capabilities. An overview of the methodology is shown in the following four figures. There are three parts: Experiment Design (Fig. 1.1), Experiment Impacts (Figs. 1.2 and 1.3), and Optics Impacts (Fig. 1.4).

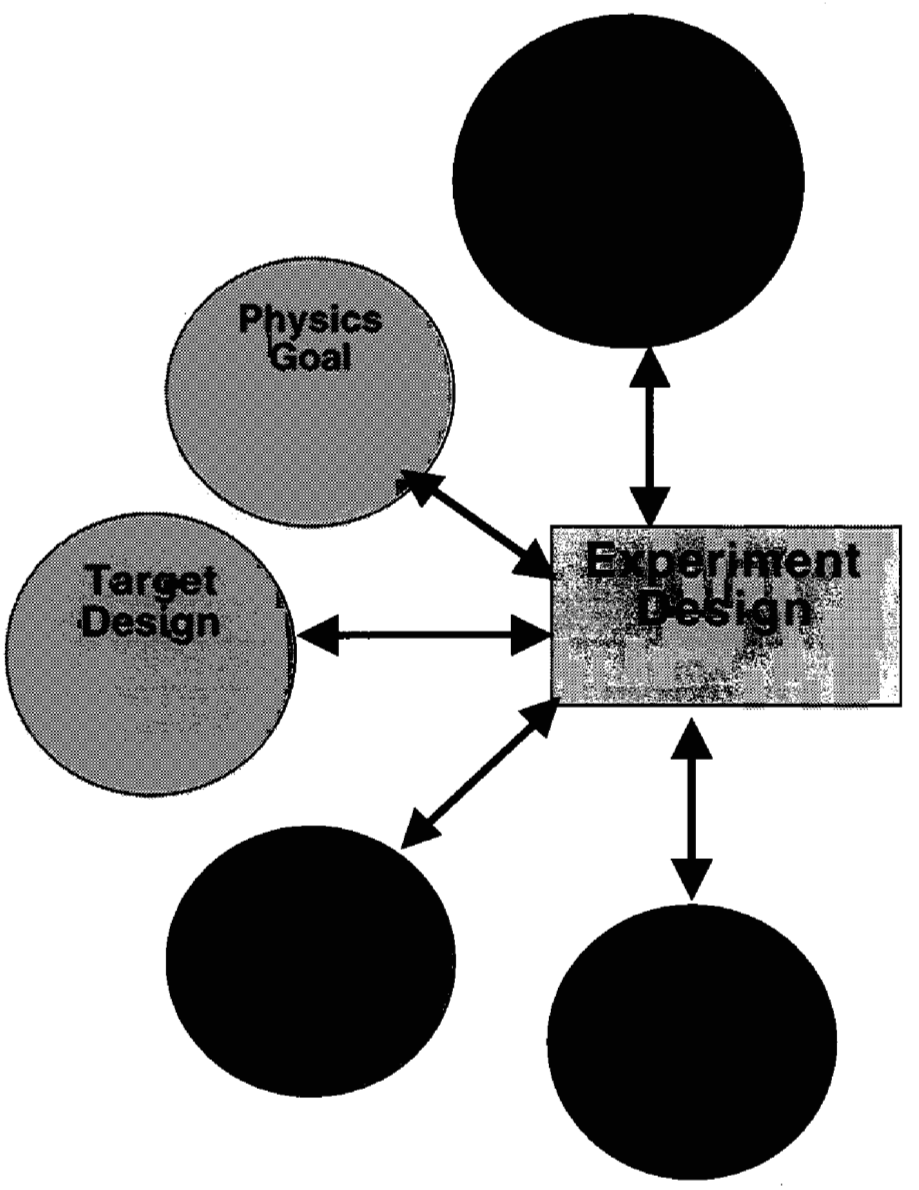

Figure 1.1 Experiment Design includes consideration of several inputs. 


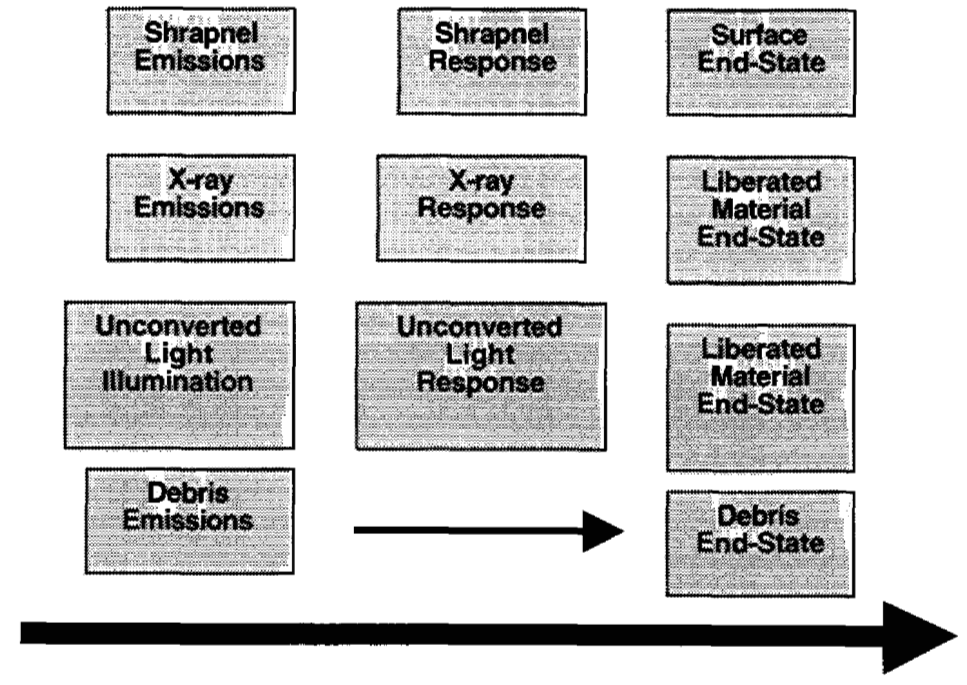

Figure 1.2 Experiment Impacts include shrapnel, x-rays, unconverted light, and debris considerations.

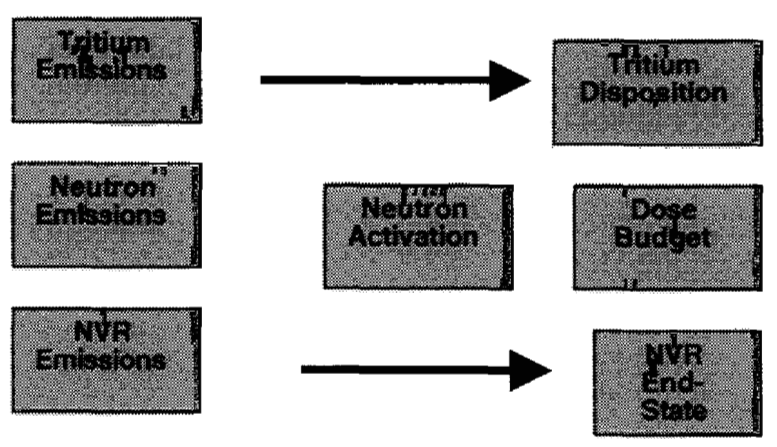

Figure 1.3 Experiment Impacts also include, when applicable, consideration of tritium, neutrons, and non-volatile residue. 


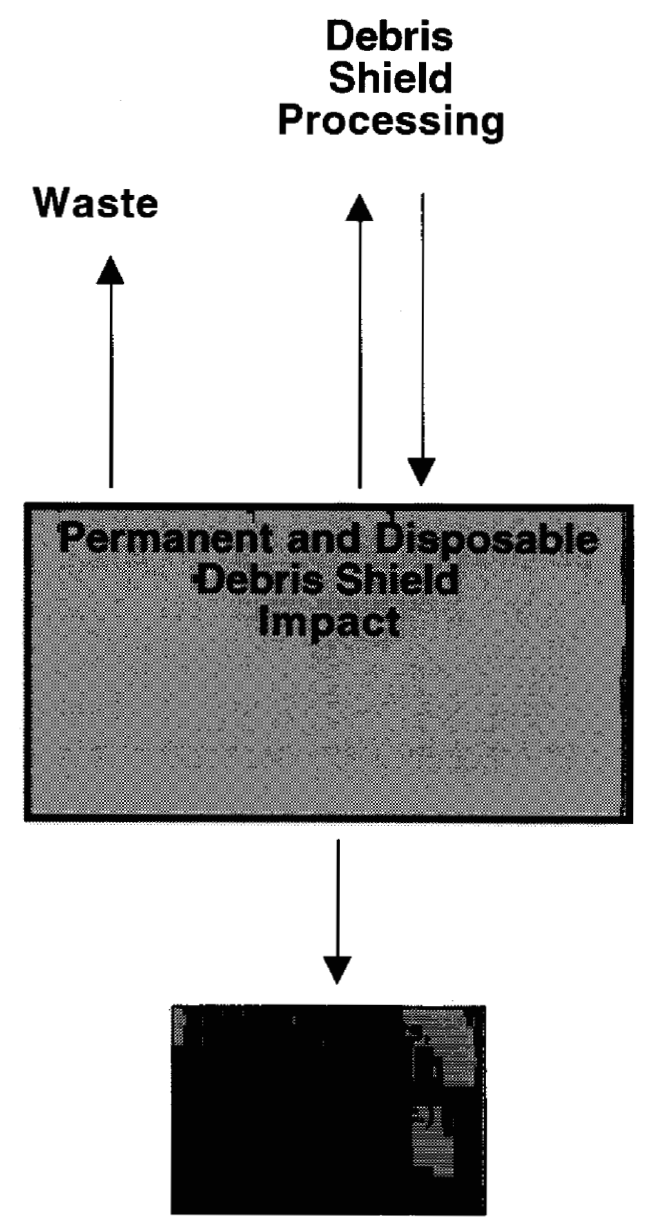

Figure 1.4 Optical impact on the debris shields (and possibly disposal debris shields) examined to establish a cost figure-of-merit. Methods to reduce costs, e.g., new materials for shields, evaluated as a cost saving method.

In the following section on methodology, each of the three major parts is discussed in more detail and the computational method is explained. In section 3 , a description is given for a planned set of NIF experiments using a $\mathrm{Au} / \mathrm{CH}$ hohlraum and laser energies in the $200-900 \mathrm{~kJ}$ range. In section 4, we show how the methodology is applied to this set of experiments. In the final section, we discuss the additional capabilities (both computational and experimental) that are needed to extend this methodology to a wider range of NIF experiments and to improve our evaluation of a cost figure-of-merit. 


\section{METHODOLOGY}

\subsection{Experimental Design}

An important aspect of the methodology we are developing is a cost figure-of-merit that can be used to evaluate various options in obtaining an optimum experimental design. As shown in Fig. 1.1, there are several inputs that must be considered in coming up with an appropriate NIF experimental design. When designing experiments for initial operation of the NIF, one has the added complication that the available diagnostics and laser parameters are constantly changing and have a major impact on what are reasonable physics goals as a function of time. It is critical that people developing NIF experimental design think through different ways to obtain a given physics goal that uses different target designs, various diagnostic configurations, and different shielding methods. The cost of obtaining the physics information, in the context of impact on the NIF debris shields, can vary greatly when the different options are considered. For example, a shield that becomes a major source of shrapnel leading to very short debris shields lifetimes might be able to be removed from the design by changing aspects of the target/diagnostic configuration. If the shielding is essential to obtain the physics goal, the methodology present here would allow one to determine what would be an appropriate cost to develop a new shield material that would be less of a shrapnel source.

\subsection{Experimental Impacts}

Once an experimental design has been specified, one can calculate the impact of this design. In Fig. 1.2, we list on the left side four sources of energy that are by-products of obtaining a given physics goal. The first step of the our methodology is to determine these sources of energy using a combination of detailed 1,2 and 3D numerical calculations, experimental measurements, and various models that allow one to interpolate and extrapolate over a wide range of experimental designs. The next step is to calculate the response when these sources of energy interact with the NIF target components and chamber. The last step is to calculate the final state of the debris shields following the shot. This including the number, size, and type of shrapnel produced craters and the state of deposited debris on the debris shield. This debris can come from x-ray ablation of the first wall and other facing components, unconverted light ablation of the beam dumps, and all sources of direct target debris. (The response of the debris shields to craters and debris is discussed in section 2.3 on optical impacts.) We give below some details on how one calculates experimental impacts associated with shrapnel, $x$ rays, unconverted light, and debris. The experimental impacts associated with tritium, neutron, and NVR emissions (Fig. 1.3) are not discussed in this report. 


\subsubsection{Shrapnel}

The calculation of the 3D spatial distribution of shrapnel, including size and velocity distribution of the droplets/fragments originating from complex target/diagnostic configurations, is an extremely challenging aspect of our methodology. An accurate calculation of shrapnel is critical in the determination of the cost figure-of-merit for a given experimental design in all situations, i.e., with and without the use of disposable debris shields. When disposable debris shields are not use a large number of craters can be created when the shrapnel strikes the unprotected permanent debris shields. The lifetime of the optic will depend critically on how much light is scattered by these craters and if the craters grow in size with subsequent shots. Debris also plays a role in reducing light reaching target center in subsequent shots and in reducing the damage threshold of the optic. When disposable debris shields are used, an accurate determination of the amount and state of debris that is deposited on the debris shields is less critical but it is essential to know the number of shrapnel fragments that could penetrate or cause rear surface spall of a disposable debris shield. Material deposited on and craters formed on the permanent as a result of penetration and/or spall will be an important aspect in determining the lifetime of the optic.

In general, shrapnel is produced from portions of the target/diagnostic configuration that are between 1 and $10 \mathrm{~cm}$ from target center. However, details of what happens within $1 \mathrm{~cm}$ of target center in terms of $\mathrm{x}$-ray generation and kinetic energy in debris can greatly affect the formation and acceleration of shrapnel. (Exact distances depend on the experimental design including laser energies.) For most experiments, material within $1 \mathrm{~cm}$ is vaporized and objects further than $10 \mathrm{~cm}$ are not broken up into small droplets/fragments that are accelerated to high velocities. In the NIF experimental design being assessed in this report, a potential source of shrapnel is a $40-\mu \mathrm{m}$ thick Ta pinhole array located $5 \mathrm{~cm}$ from target center. A source of shrapnel that is not present in this experimental design, but is being considered for other experiments, is unconverted-light shields that are attached to the hohlraum and extend out to of order $3 \mathrm{~cm}$ from target center.

Our methodology to calculate shrapnel generation, in the current state of development, is to divide the problem into parts that can be modeled using appropriate codes. The long-term goal, which is discussed in more detail in the last section, is to have a single code that calculates shrapnel generation in a more self-consistent method than is now possible. When we divide the problem, the calculation of $3 \omega$ laser light absorption, generation of $\mathrm{x}$ rays, and motion of very high temperature plasmas is done using a hydrodynamic/radiation transport code such as LASNEX. A number of different codes including LASNEX can be used to calculate the absorption of the unconverted $1 \omega$ laser light that extends out to approximate $3 \mathrm{~cm}$ from target center. Material that is melted by unconverted light can be accelerated by $x$ rays and debris wind. For objects outside of the unconverted light cone, the absorption by plasma $x$ rays generated near target center can the major source of energy that results in ablation, melting and spalling of solid fragments. We use a hydrodynamic/radiation transport code such as LASNEX to calculate the absorption of the relatively short pulse of $x$ rays in these objects. The resulting conditions are then transferred to another code, e.g., L2D at SRI or ALE3D, to calculate melting and droplet/fragment generation. At this time, the size distribution of 
the droplet/fragments is calculated using relatively simple relations. For example, the average droplet diameter is given by

$$
S_{\text {avg }}=3.6\left(\gamma / \rho \varepsilon^{2}\right)^{1 / 3},
$$

Where $\gamma$ is the surface energy per unit area, $\rho$ is the density, and $\varepsilon$ is the strain rate. There is another simple relation that gives the surface energy as a function of temperature out to the critical temperature using van der Waals constants. The $\varepsilon^{-2 / 3}$ scaling with strain rate means that a liquid under a higher strain will form smaller droplets as expected. For solids it is found that the average diameter is more sensitive to the strain rate with a scaling $\varepsilon^{-1}$ in many situations. These relations give the average size of the droplets/fragments. It has been observed that the size distribution is well approximated by a Poisson distribution,

$$
\mathrm{N}_{\mathrm{g}}(\mathrm{S})=\mathrm{N}_{0} \exp \left(-3 \mathrm{~S} / \mathrm{S}_{\mathrm{avg}}\right),
$$

where $\mathrm{N}_{g}(S)$ is the number of fragments per unit volume with diameters greater than $S$, and $\mathrm{N}_{0}$ is the total number of droplets/fragments per unit volume. We use this procedure using the L2D code to calculate shrapnel from the Ta pinhole array discussed in the next section.

Given a size and velocity distribution of shrapnel of a given composition the calculation of craters sizes on an unprotected permanent debris shield is calculated using an empirical formula,

where

$$
\begin{aligned}
& \mathrm{D} / \mathrm{L}=\beta\left[\alpha \rho v^{2} / \mathrm{Y}\right]^{1 / 3}, \\
& \alpha=\operatorname{Min}\left\{0.1 \rho v^{2} / Y, 1\right\},
\end{aligned}
$$

$\mathrm{D}$ is the depth of the fracture crater, $\mathrm{L}$ is the diameter of the incoming fragment, $\mathrm{b}$ is the ratio of the fracture crater to the plastic crater $(b=10$ for fused silica), $r$ is the density of the fragment, and $Y$ is the dynamic compressive yield strength $(Y=1 \mathrm{GPa}$ for fused silica). This formula is consistent with data taken using gas gun accelerated stainless steel spheres. We are in the process of developing models to be used when the permanent debris shield is protected by a thin disposable debris shield. Of primary interest are fragments that could penetrate or cause back-surface spall of the disposable debris shield. 


\subsection{2 $\mathrm{X}$ rays}

As discussed above, the calculation of $\mathrm{x}$-ray generation is done using a hydrodynamic/radiation transport code such as LASNEX. In general, a large fraction of the NIF input laser energy is converted to $x$ rays. For objects within approximately 10 $\mathrm{cm}$ of target center the $\mathrm{x}$ rays are important in creating and accelerating shrapnel droplets/fragments. At larger distances, the x-ray ablation of facing components, including the first wall, can be a major source of debris. Ablation of the first wall by $x-$ rays is of primary concern for yield shots.

For experimental designs that use hohlraums, the $\mathrm{x}$ ray emission is generally not isotropic. $X$ rays escaping through the laser entrance holes (LEH's) are a major source of late-time cooling of hohlraums. The $x$-ray emission along the waist of the hohlraum comes from late-time hohlraum wall emission and $x$ rays coming from the plasma plume that is ejected out of the LEH's. If the plasma ablated from the edge of the LEH's and the inside hohlraum walls causes the LEH's to close, the resulting higher temperatures cause the wall emission to be significantly higher. This is of particular interest if there is a component close to the hohlraum but located in the direction of the waist. This is the case for the experimental design discussed below where the Ta pinhole array is located $5 \mathrm{~cm}$ from target center. The effect of LEH closure has been studied with 1D LASNEX simulations where an effective LEH is assumed to close approximate $10 \mathrm{~ns}$ after the laser pulse or is assumed to never close. In fig. 2.1, we show results for two laser energies (1.8 and $0.45 \mathrm{MJ})$ and two Au wall thickness $(10$ and $30 \mu \mathrm{m})$. The simulations are $1 \mathrm{D}$ hohlraums with an inside surface area corresponding to a full-scale NIF hohlraum with a length of $1.0 \mathrm{~cm}$, a diameter of $0.6 \mathrm{~cm}$ and LEH diameter of 0.3 $\mathrm{cm}$. Given that we scale the $y$-axis with laser energy, it is easy to see that higher energy gives higher conversion efficiencies. The highest overall conversion efficiency of laser light to escaping $x$ rays is $82 \%$ for $1.8 \mathrm{MJ}, 10 \mu \mathrm{m}$ walls and an open LEH. The lowest is $34 \%$ for $0.45 \mathrm{MJ}, 30 \mu \mathrm{m}$ walls, and a closing LEH. To obtain the angular dependence shown in Fig. 2.1 from the 1D calculations, we assume that the LEH emission is Lambertian peaked at 0 degrees and that the wall emission is isotropic. In all cases there is a drop in fluence as ones goes to 90 degrees where the only contribution if from wall emission. The differences between the open and closing LEH 1D models motivated a 2D study of LEH closure to $x$ rays.

We have completed two 2D LASNEX simulations of a full-scale NIF hohlraums run out to late times for energies of 0.45 and $1.8 \mathrm{MJ}$. We will restrict our attention to the $0.45 \mathrm{MJ}$ case in this report because the results are more relevant to the energies planned for the experiment discussed in the next section. The Au wall thickness is $12 \mu \mathrm{m}$ for this $2 \mathrm{D}$ run. The simulation was run out to approximately $10 \mathrm{~ns}$ in a Lagrangian mode at which point the mesh was fixed and the simulation was continued out to $100 \mathrm{~ns}$ in an Eulerian mode. Shear associated with plasma leaving the LEH, as well as plasma from the outside wall interacting with the ejected plasma, made running in purely Lagrangian mode very difficult. There is some loss of plasma at the edge of the mesh in Eulerian mode but the issue of LEH closure can still be studied. In the last section, we discuss the use of a 3D ALE (Arbitrary Lagrangian Eulerian) code, HYDRA, which shows promise for late-time hohlraum simulations. The angular dependence of the $x$ rays integrated over energy at a series of times from 5 to $100 \mathrm{~ns}$ is shown in Fig. 2.2. At 5 and $10 \mathrm{~ns}$ 
there is very little emission observed at 90 degree. At the peak of the $x$-ray emission at $15 \mathrm{~ns}$, the emission at 90 degree is within a factor of 10 of the peak, which occurs around 40 degrees. This angle has a very good view of the inside wall of the hohlraum. At 0 degrees, one is looking along the hohlraum axis and through the LEH on the other side. The emission on axis is calculated to be comparable to the emission at 90 degrees at this time. Only $5 \mathrm{~ns}$ later, there is very little angular dependence to the $\mathrm{x}$-ray emission with only a slight minimum on axis. In the next $10 \mathrm{~ns}$, the emission decreases by a factor of approximately 10 and there is clear, but still weak, weak angular dependence have a maximum at 90 degrees. This trend continues out $100 \mathrm{~ns}$ where the emission is clearly a function angle associated with cross-section area of the hohlraum seen at that angle. In Fig. 2.3, we give the time integrated fluence as a function of angle. We have maximum around 45 degrees and the fluence at 90 degrees is down by less than a factor of 2 while the fluence on axis is down by factor of 4 from the peak. Comparing this curve to the two $10 \mu \mathrm{m}$ curves in Fig. 2.1b, the ratio of the fluence at 90 degrees to the peak fluence would indicate the closed LEH model is in better agreement. It must be noted that the $2 \mathrm{D}$ runs do not have a capsule at the center of the hohlraum, which would have some effect on the angular dependence of the $x$ rays.

a)

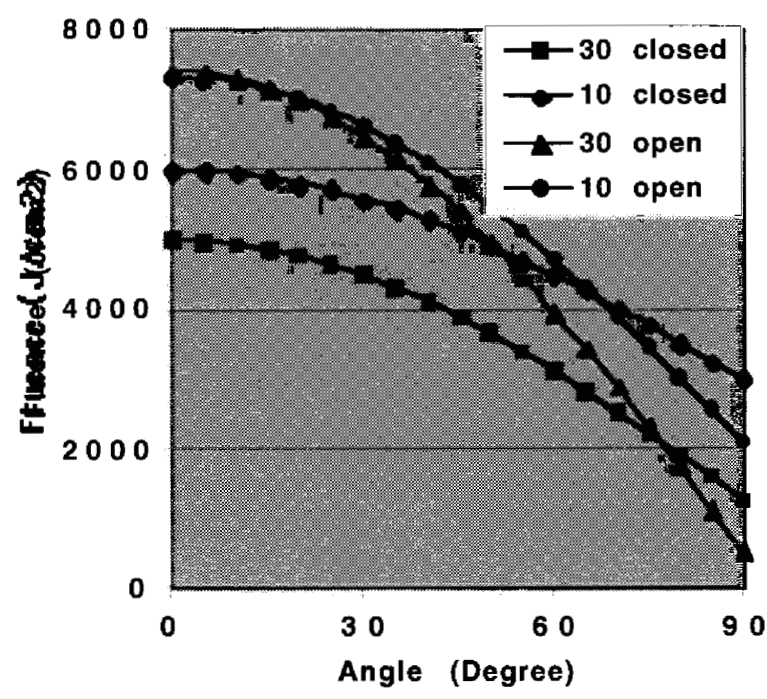

b)

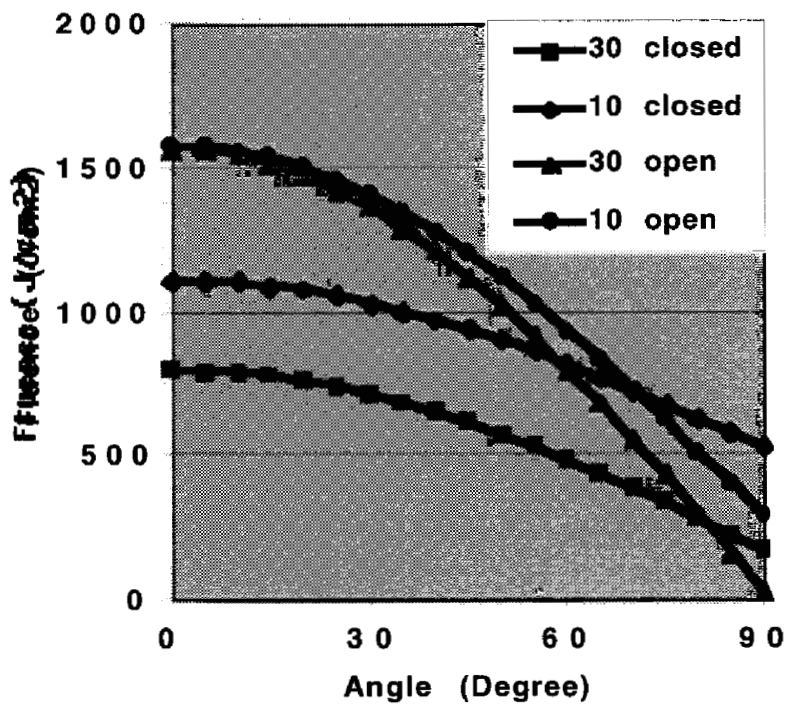

Figure 2.1 X-ray fluence at $5 \mathrm{~cm}$ from target center as a function of angle from the hohlraum axis for gold wall thickness of 10 and $30 \mu \mathrm{m}$ using $1 \mathrm{D}$ simulations.

a) full NIF energy of $1.8 \mathrm{MJ}$ and b) $1 / 4$ of full NIF energy at $450 \mathrm{~kJ}$ 


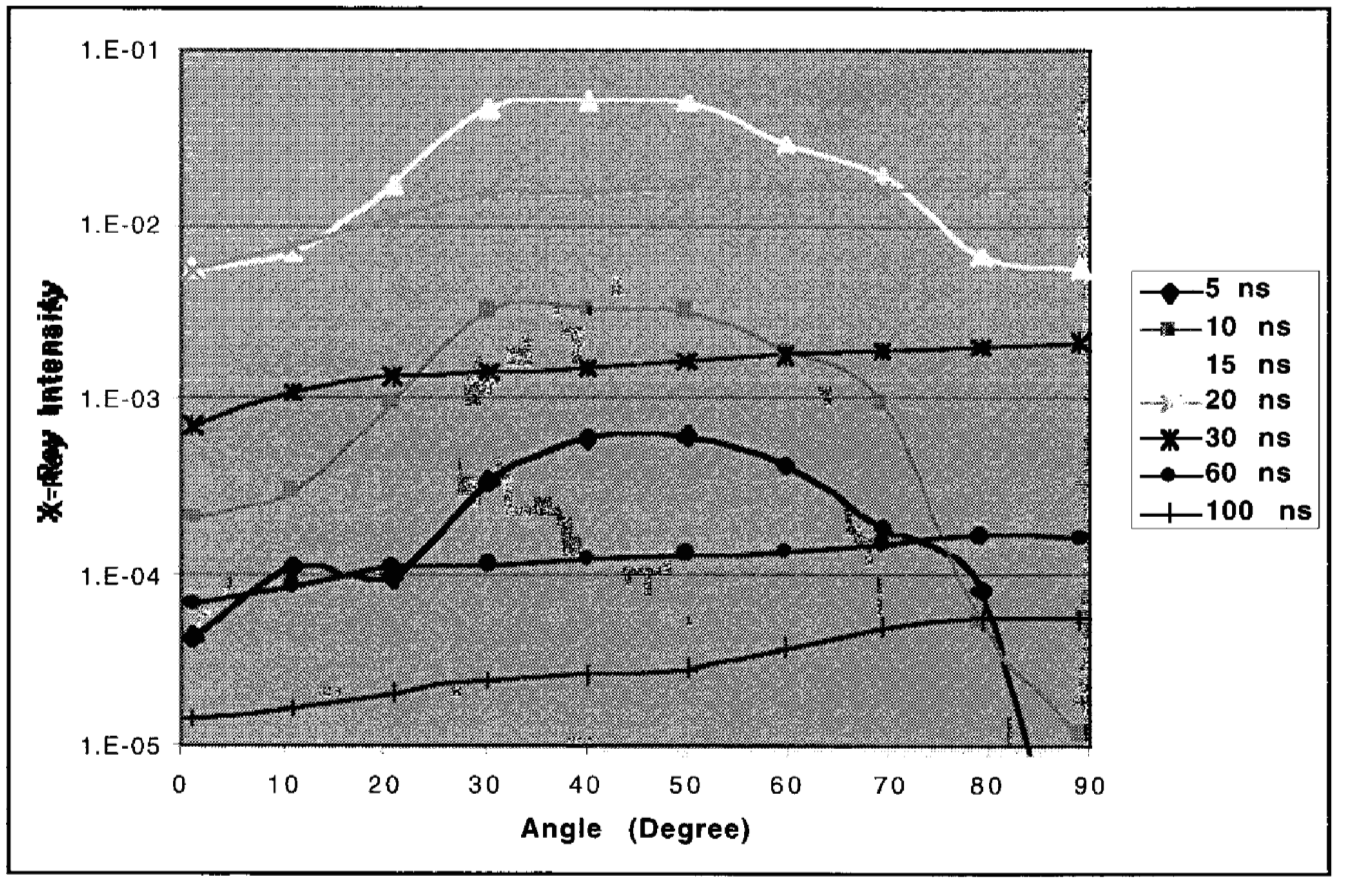

Figure 2.2 X-ray intensity as a function of angle from the hohlraum axis for a gold wall thickness of $12 \mu \mathrm{m}$ at 7 different times using a 2D LASNEX simulation.

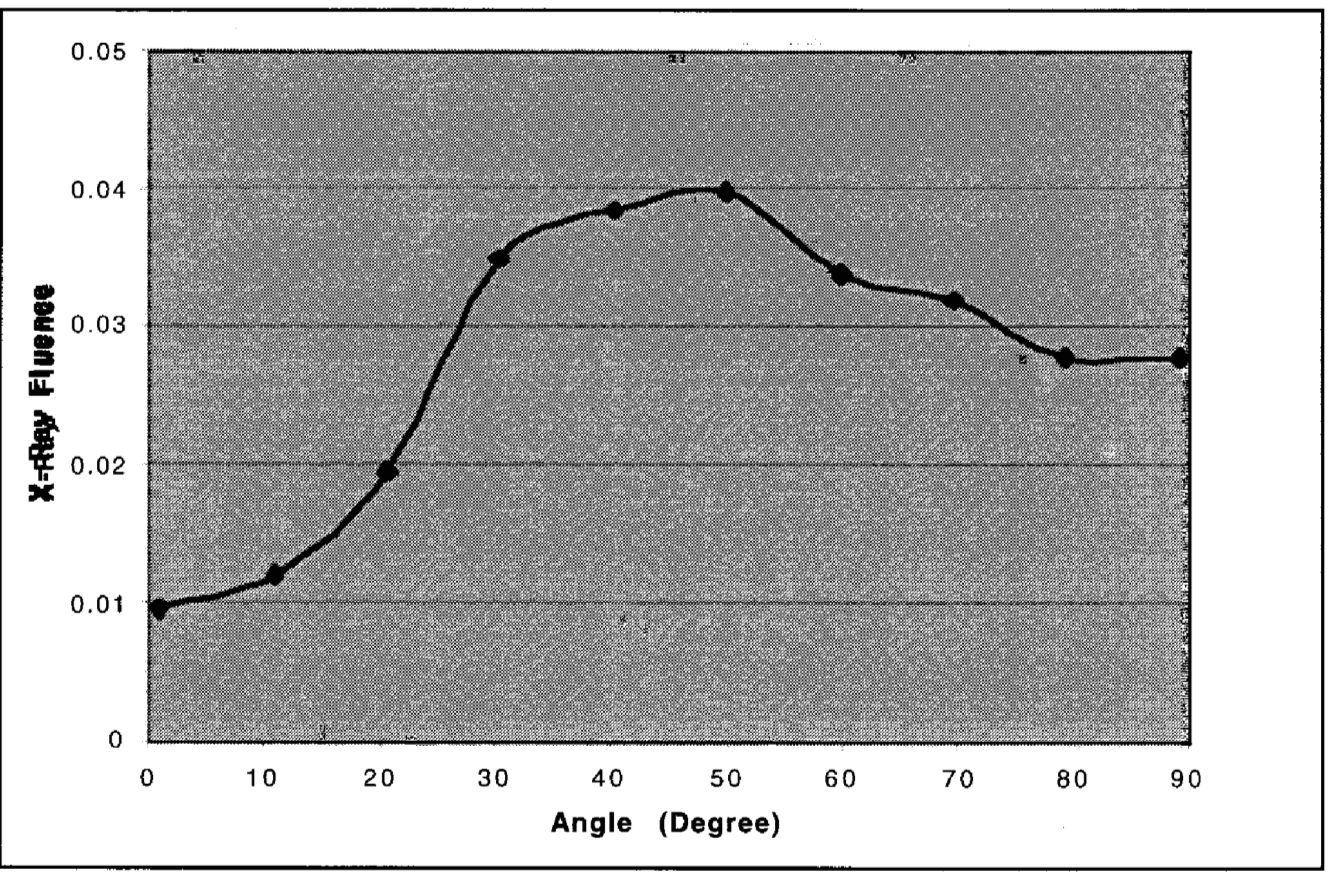

Figure 2.3 X-ray fluence as a function of angle from the hohlraum axis for a gold wall thickness of $12 \mu \mathrm{m}$ using a 2D LASNEX simulation. 


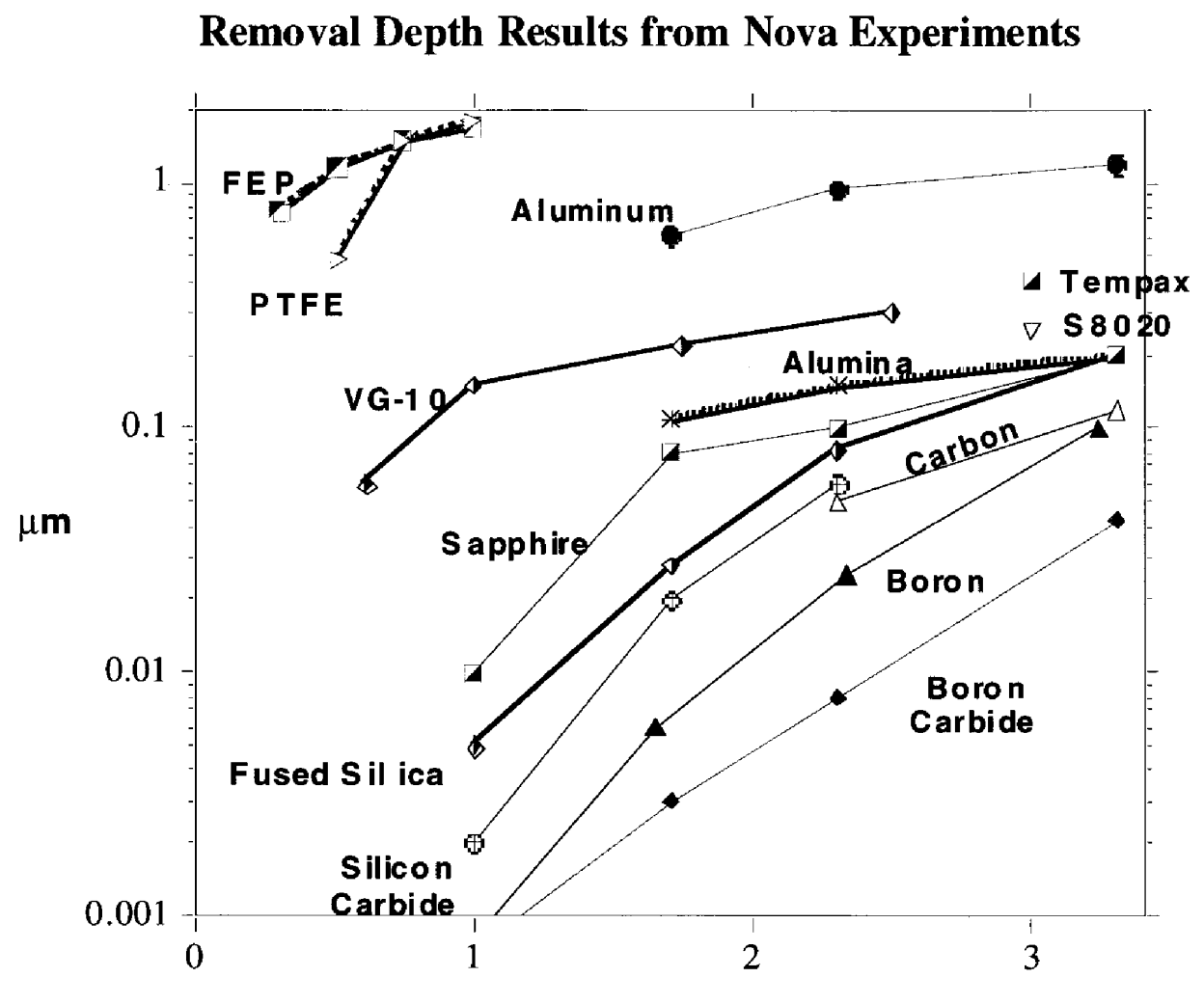

$X$-ray Fluence $(\mathrm{J} / \mathrm{cm} 2)$

Figure 2.4 Example of data collected on Nova giving the removal depth as function of $x$-ray fluence for a wide range of materials.

Once the x-ray angular fluence has been determined, one must determine the response of different target and chamber components to the $\mathrm{x}$-rays. The response can include ablation, melting, spalling. In section 2.2.1, we discuss the response associated with shrapnel droplets/fragments associated with melt and spall. This is discussed more in section 4 in the context of a Ta pinhole array located $5 \mathrm{~cm}$ from the hohlraum. For objects located $10 \mathrm{~cm}$ and more from target center, the major concern is the amount of ablated material that gets deposited on the debris shields. There was an experimental program on Nova to measure x-ray ablation depth as shown in Fig. 2.4. In addition, there was a computer code, ABLATOR, that was written to study low-fluence x-ray ablation. In Fig. 2.5, we give an example of ABLATOR calculations for stainless steel at different fluences and spectra. For higher fluences, there is clear reduction in ablation for colder $\mathrm{x}$-ray sources. This is important for components that see primarily wall emission as compared to emission coming out of the LEH's. For fluences greater than of order $10 \mathrm{~J} / \mathrm{cm}^{2}$, the x-ray opacity during the x-ray pulse often becomes a function of temperature and the cold-opacity approximation used in ABLATOR is not valid and other codes, e.g., LASNEX must be used. 


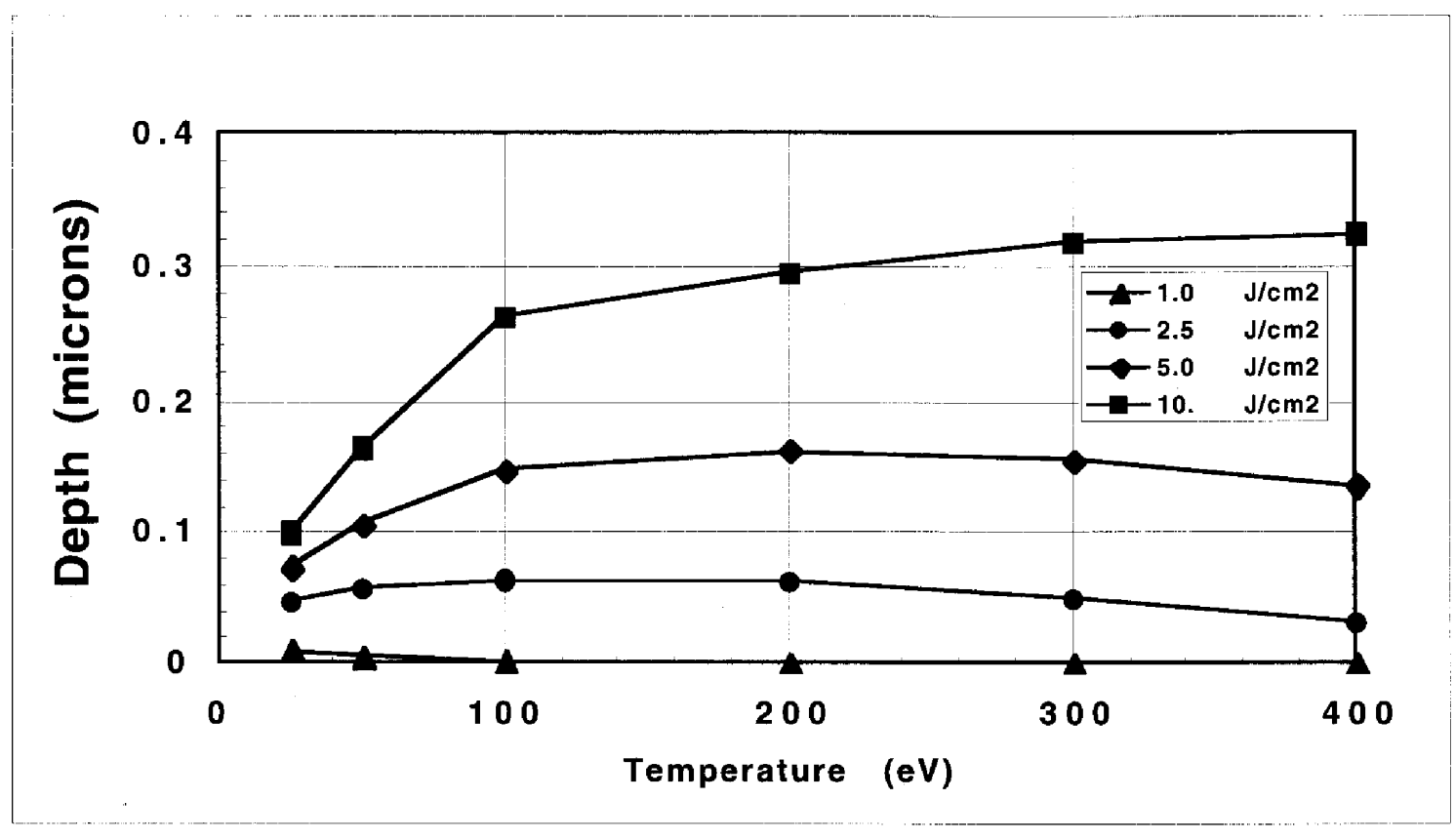

Figure 2.5 Ablation depth in stainless calculated using ABLATOR for different $x$-ray fluences and spectra associated with different blackbody temperatures and $20 \mathrm{~ns}$ pulses.

\subsubsection{Unconverted light}

Unconverted light can be important both at target center and at the beam dumps located on the chamber wall. The NIF is designed to have the inside edge of the unconverted light miss target center by approximately $0.3 \mathrm{~cm}$ with the outside edge extending out to approximately $3 \mathrm{~cm}$. The intensity of the unconverted light in the region is sufficient to melt a significant amount of material. The resulting droplets can be accelerated by $x$ rays and debris wind to high enough velocities such that the droplets can create craters on the debris shields. The experimental design discussed in the next section does not have any components that get significant exposure to unconverted light near target center. In this report we restrict our attention with regard to unconverted light to ablation at the beam dumps.

The amount of unconverted light is a strong function of the input intensity with very poor conversion at low intensity. The conversion is shown in Fig. 2.6. In general, the overall conversion is around $50 \%$ for many pulse shapes being considered for NIF. If the unconverted light is not absorbed near target center it is absorbed when it reaches the far wall. The mass of stainless steel ablated as a function of fluence is given in Fig. 2.7. The first wall on NIF consists of stainless steel louvers that are designed to capture approximately $90 \%$ of the ablated mass. It is shown in section 4 , even with this $90 \%$ capture, that ablation by unconverted light can be the major contribution of debris to the chamber. 


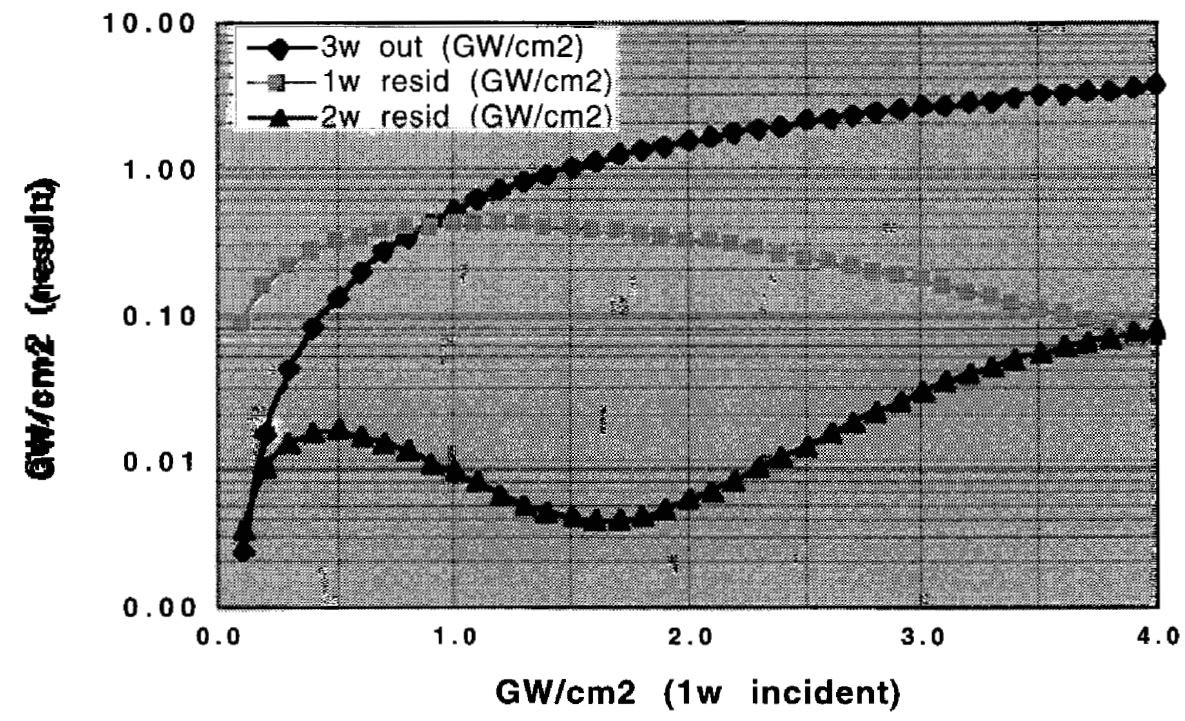

Figure 2.6 The conversion efficiency to $3 \omega$ as a function of incident $1 \omega$ light.

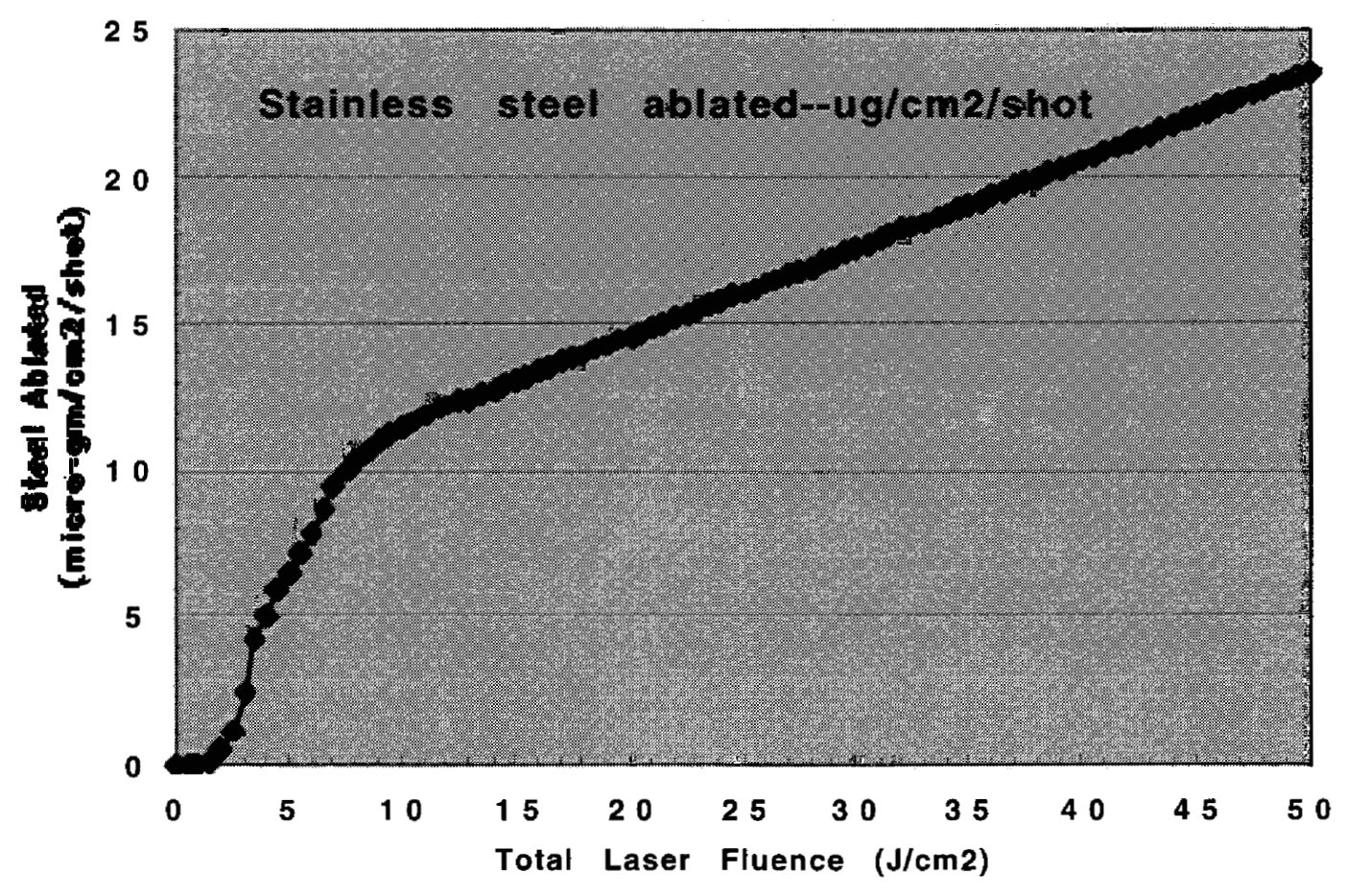

Figure 2.7 The quantity of stainless steel ablated as a function of laser fluence.

\subsubsection{Debris}


The amount of material vaporized at target center must be added to the other ablated material discussed above. From measurements on Nova, we know that the material from vaporized target does not deposit on the debris shields isotropically. However, to get an estimate we often assume an isotropic distribution of debris. In addition, we know that the form, e.g., size of deposited particles, of the debris is important in determining the reduction in transmission as a function of deposited mass. Different materials from the target are expected to have different size distribution on the debris shields. Debris from other sources, e.g., beam dumps, would also deposit differently. At this time, we use a simple linear relationship obtained from Nova debris shields that gives loss in transmission as a function of deposited mass.

\subsection{Optical Impact}

One component of optical impact is discussed above in section 2.2.4 associated with loss of transmission in the debris shield as a result of deposited mass. This will determine the rate that debris shields must be cleaned if disposable debris shields are not being used. If the laser is being run at fluences where the debris on the shields is sufficient to lower the damage threshold such that damage sites are being formed, there can be a clear benefit to remove and clean the debris shields more frequently. In section 2.2.1, the formation of craters by shrapnel fragments is discussed. These craters scatter the laser light and reduce the amount of light that reaches target center. Given that these craters are nor removed during cleaning, the number and size of these craters determine the lifetime of debris shield. This lifetime can be greatly reduced if the laser is being operated at a fluence level that causes the craters to grow in size. The growth rate of shrapnel induced craters is an area of on going research. At this time, we use the growth rate measured for laser induced damage sites to estimate the growth rate for shrapnel induced craters.

\section{TARGET AND EXPERIMENTAL DESCRIPTION}

\subsection{Experiment Description}

This experiment is designed to examine the implosion of various capsule designs in the presence of various $x$-ray drives that are intended to simulate the foot of the ignition pulse. We assume that the ratio of the drive pulse to the foot pulse is $5: 1$. Further, since this hohlraum is reduced by about $1 / 3$ in length, we scale the laser accordingly as well. Therefore, a $12 \mathrm{~ns}$ pulse with $300 \mathrm{~kJ}$ for this target would provide similar drive conditions as the ignition target using the full $1.8 \mathrm{MJ}$ and $450 \mathrm{~kJ}$ in the foot with a duration of $18 \mathrm{~ns}$. For the $450 \mathrm{~kJ}$ and $900 \mathrm{~kJ}$ shots, the energy not used in the foot is delivered in a $2 \mathrm{~ns}$ main pulse starting at $10 \mathrm{~ns}$. The measured response of the capsule, for example the compression ratio (initial radius divided by the final radius) and the symmetry of implosion (variation in radius during the implosion), is determined by backlighting the hohlraum-capsule assembly with a Ti disk irradiated with 8 beams of NIF. The backlit image is collected using a gated detector made up of microchannel plate strips. 


\subsection{Target}

The main part of the target is a small Au hohlraum that is tamped on its exterior with 100 microns of $\mathrm{CH}$. This is intended to reduce the total mass of metal condensate in the chamber, provide stability for the small amount of high $\mathrm{Z}$ material remaining, and delay $x$-ray emission from the hohlraum walls until the backlit image can be collected. At the center of the hohlraum is a $1.5 \mathrm{~mm}$ diameter, 30-micron thick capsule made of Ge-doped CH. The capsule is filled with DD or $50 \% \mathrm{D}$ and $50 \% \mathrm{H}$ with about $1 / 2 \%$ Ar to a total pressure of 50 atmospheres. It is held in place with a 2-micron thick polyimide layer. The hohlraum requires a gas loading to retard wall blowoff. This is provided by filling the hohlraum with $2 \mathrm{mg} / \mathrm{cc}$ of a $\mathrm{H} / \mathrm{He}$ mixture where the two species are equimolar. A 0.8-micron thick polyimide window seals each 3-mm diameter laser entrance hole. The backlit image is collected through two 2-mm diameter circular regions of the target where the wall is thinned to just 2-microns of Au from the 10microns of Au that makes up the rest of the wall.

\begin{tabular}{|c|c|c|}
\hline Component & $\begin{array}{c}\text { Density } \\
\text { (g/cc) }\end{array}$ & $\begin{array}{l}\text { Mass } \\
(\mathrm{mg})\end{array}$ \\
\hline Au wall & 19.3 & 18.71 \\
\hline $\mathrm{CH}$ wall (polyethylene) & 0.96 & 12.65 \\
\hline CH capsule & 0.96 & 13.6 \\
\hline Ta x-ray shields (2) & 16.6 & 1.99 \\
\hline Stalk (Target, BL) & 2.3 & 1.8 \\
\hline Total & & 48.75 \\
\hline
\end{tabular}

Table 3.1 An accounting of the mass by material type in the target. 


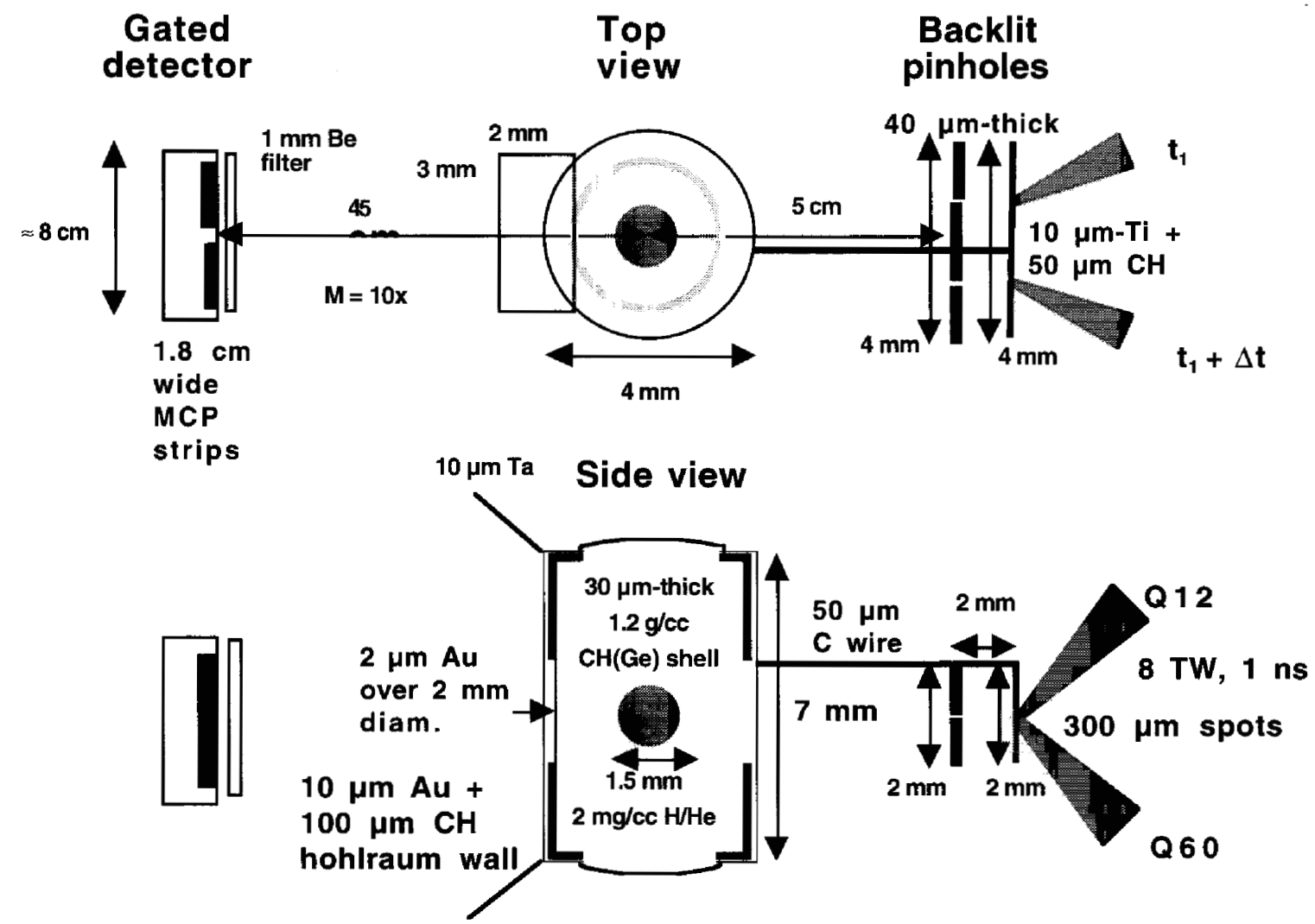

Figure 3.1 Conceptual Design of a non-yield implosion experiment

\subsection{Shields}

There are two x-ray shields mounted to the front face of the hohlraum on the side of the gated $x$-ray diagnostic. The purpose of the shield is to prevent $x$-rays from the debris plume that exits the LEH from exposing the MCP to a sufficient flux of $x$-rays that would degrade the experimental fidelity or dilute the accuracy of the data. The size of the shields is based on preventing the hot debris from moving beyond the shield before the diagnostic has finished taking data. The shields will be coated with a $C$ paint to retard $x$-ray emission when the unconverted light is incident on this surface. The unconverted light average intensity could exceed $1.5 \times 10^{12} \mathrm{~W} / \mathrm{cm}^{2}$.

\subsection{Diagnostics}

There are four diagnostics that will be used with this experiment: two SXIs (at $161^{\circ}$ and $18^{\circ}$ ), the DMIX (at $36^{\circ}$ ), and a gated detector at $45 \mathrm{~cm}$. The stand-off to each instrument is $50 \mathrm{~cm}$ except for the gated detector, which is at $45 \mathrm{~cm}$. Each diagnostic is protected across its diameter facing chamber center by a $1 \mathrm{~mm}$ thick disk of Be. 


\subsection{Target Positioner Tip}

The target positioner is protected by a $10 \mathrm{~cm}$ diameter plate that is coated with plasma sprayed $\mathrm{B}_{4} \mathrm{C}$ that is in turn backed by crushable $\mathrm{Al}$ foam to retard the shock from the $\mathrm{x}$ ray loading. The target is held by a $100 \mu \mathrm{m}$-thick boro-silicate glass rod that is $10 \mathrm{~cm}$ long.

\section{APPLICATION OF METHODOLOGY}

The experimental design discussed in the last section was developed with our new guidelines for debris and shrapnel per shot in mind. The total allowed debris mass per shot is $400 \mathrm{mg}$ and the total allowed shrapnel mass per shot is $5 \mathrm{mg}$. The shrapnel mass assumes fragments with an average size of $10 \mu \mathrm{m}$ and a velocity of $1000 \mathrm{~m} / \mathrm{s}$. These guidelines are for low fluence operation where one can neglect the effects of crater growth and reduced damage threshold associated with debris. These guidelines assume weekly cleaning of the debris shields, removal of the debris shields every two months, and a shot rate of 15 shots per week. The debris mass limit motivated the use of $\mathrm{Au} / \mathrm{CH}$ hohlraum with the thought that the mass associated with the $\mathrm{CH}$ will be pumped out of the chamber. The design does not have any massive unconverted light shine shields that could become both a debris and shrapnel source. The target support rod and the pinhole array support have only have masses of order 0.16 and 0.04 $\mathrm{mg} / \mathrm{cm}$, respectively. (It is possible that the supports will have to be made thicker as these numbers are an estimate of how thin is possible.) The combined mass for a $5 \mathrm{~cm}$ length of the two supports is of order $1 \mathrm{mg}$. The most massive object that has the potential to become shrapnel in this design is the Ta pinhole array with a mass of 5.3 mg.

There are three major sources of debris: first, the target itself; second, the mass ablated from the beam dumps by unconverted; and third light the mass ablated by $\mathrm{x}$-rays from all facing components. For shrapnel, we restrict our attention in this report to the Ta pinhole array. We expect the shrapnel from the supports to meet the guidelines given their masses. For the target mass, we make the reasonable assumption that the entire target is vaporized for all three energies of interest. Based on simulations of the hohlraum, it is clear that it is vaporized. The only question is the thin $10 \mu \mathrm{m}$ thick Ta shield (mass is $1 \mathrm{mg}$ ) that is attached to the hohlraum and extends out of order $2 \mathrm{~mm}$. However, estimates of $\mathrm{x}$-ray loading and its contact to the hohlraum indicate that it should also be vaporized. We next discuss the mass that is expected from the beam dumps for each of the three laser energies. We account for the different pulse shapes and number of beams that are being planned for each of the different energies. This is followed by an estimate of the $x$-ray loading on all the facing components to determine ablated mass. We finish this section with a detailed calculation of ablation, melting, and spall of the Ta pinhole array as a result of $x$ ray loading. Prior to our calculation of debris and shrapnel, we give a timeline of various events that happen in the chamber. 


\subsection{Timeline of Disassembly}

A timeline is useful to deconvolve the various effects for this very complex disassembly. One is listed below. This time line also includes various assumptions that either simply allows the calculation of the timing of the event or provides other important criteria for understanding the step-by-step process. This also provides insight into how a computational capability for predicting target disassembly should be logically constructed. The timeline considers only the $900 \mathrm{~kJ}$ case.

\begin{tabular}{|c|c|c|}
\hline $\begin{array}{l}\text { Time } \\
\text { (ns) } \\
\end{array}$ & Event & Assumption \\
\hline 0 & $\begin{array}{l}900 \mathrm{~kJ} \text { of laser energy enters hohlraum, } \\
\text { striking spots on the interior wall }\end{array}$ & 500 micron best focus at LEH \\
\hline 0.006 & first $x$-rays strike capsule exterior & x-rays generated by laser light contact \\
\hline 0.01 & First $x$-rays leave LEH & \\
\hline 0.023 & First UCL strike backside of shields & \\
\hline 1.523 & First X-rays from shield back reach $\mathrm{MCP}$ & \\
\hline 4 & Diagnostic LOSs open/radiate & \\
\hline 4.17 & First $x$-rays reach pinhole assembly & \\
\hline 10 & First backlighter beam strikes $\mathrm{BL}$ & \\
\hline 10 & foot of pulse is finished & contains about $300 \mathrm{~kJ}$ of energy \\
\hline 11.7 & First $\mathrm{BL} x$-rays reach detector & \\
\hline 12 & Main pulse is finished & contains about $600 \mathrm{~kJ}$ of energy \\
\hline 12.011 & Last UCL strikes BL assembly & \\
\hline 12.013 & Last $\mathrm{x}$-rays strike capsule exterior & \\
\hline 12.023 & Last UCL strike backside of shields & \\
\hline 13 & Last backlighter beam strikes $\mathrm{BL}$ & \\
\hline 13.523 & Last shield-emitted $\mathrm{X}$-rays reach $\mathrm{MCP}$ & \\
\hline 15.7 & Last $\mathrm{BL} \mathrm{x}$-rays reach detector & \\
\hline 16.17 & Last $\mathrm{x}$-rays reach pinhole assembly & \\
\hline 20 & LEHs close to $x$-ray emission & \\
\hline 25 & Diagnostic LOSs close to $x$-ray emission & \\
\hline 54 & First $x$-rays leave LOS & 4 ns burn thru gold, 50 ns burn thru $\mathrm{CH}$ \\
\hline 55.5 & First $\mathrm{x}$-rays from target reach $\mathrm{Be}$ filter & \\
\hline 67.5 & Last $\mathrm{x}$-rays from target reach $\mathrm{Be}$ filter & \\
\hline TPD & First target debris reaches pinhole & \\
\hline TPD & Last target debris reaches pinhole & \\
\hline TPD & First target $\mathrm{x}$-rays reach TPOS protection & \\
\hline TPD & Last target $x$-rays reach TPOS protection & \\
\hline 70 & $\begin{array}{l}\text { X-rays emitted from the wall of the } \\
\text { hohlraum }\end{array}$ & \\
\hline 240 & First LEH debris clears $x$-ray shield & $1.2 \mathrm{~mm}$ length of travel at $5 \mathrm{~km} / \mathrm{s}$ \\
\hline 500 & first debris jets out laser entrance hole & $\begin{array}{l}\text { debris delays for } 10 \mathrm{~ns} \text {; moves at } 5 \mathrm{~km} / \mathrm{s} \\
\text { to center and then outwards }\end{array}$ \\
\hline 880 & debris has view to MCP & \\
\hline
\end{tabular}

Table 4.1 A step-by-step description of the target disassembly.

\subsection{Laser Energies and Unconverted Light / Beam Dump Impacts}


We consider three different laser energies: $225 \mathrm{~kJ}, 450 \mathrm{~kJ}$ and $900 \mathrm{~kJ}$. We assume that the $225 \mathrm{~kJ}$ is for a NIF with 48 of the beams operational, that at $450 \mathrm{~kJ} 96$ of the beams are operational, and that at $900 \mathrm{~kJ} 120$ of the beams are firing. The assumed 3 pulses are shown in Figure 2.3 for each beamline used for the shot.

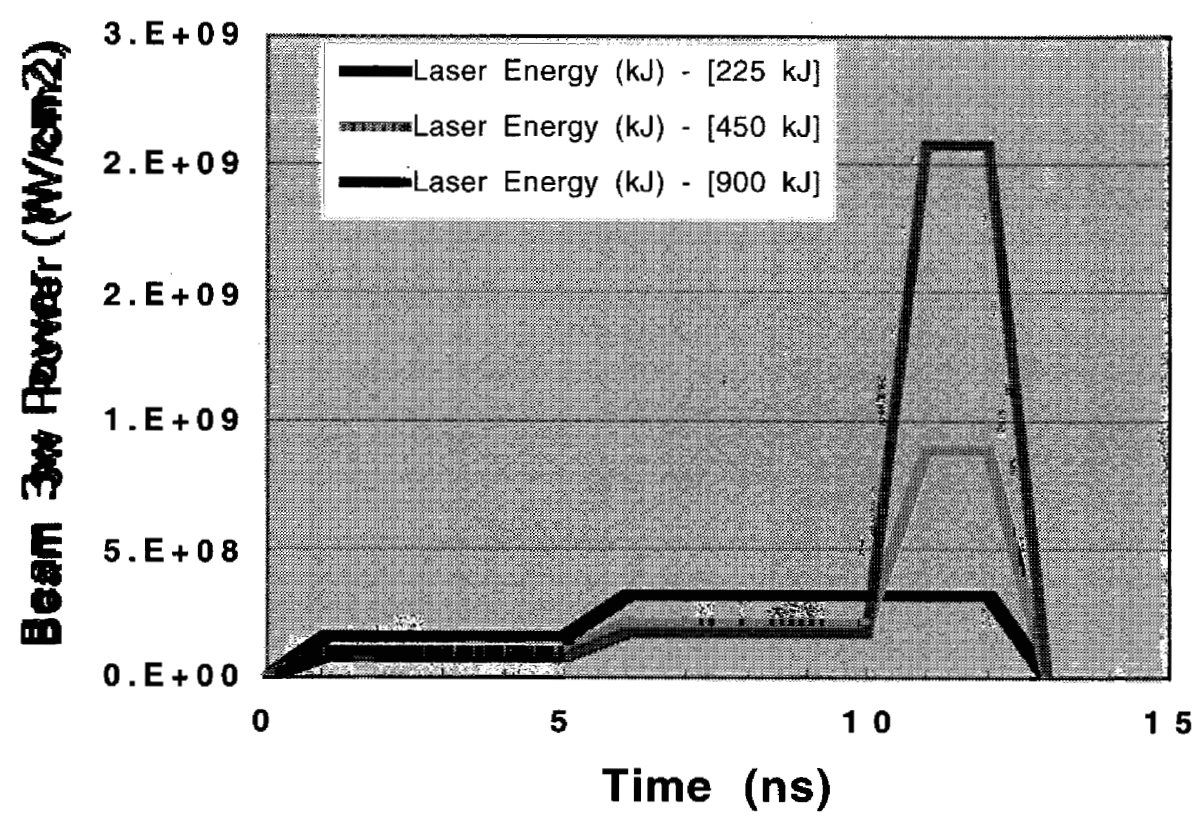

Figure 4.1 The three laser pulse shapes considered for this analysis.

The pulse length is $12 \mathrm{~ns}$ for each shot and is intended to mimic the initial part of the Haan pulse. The amount of unconverted light produced is intensity dependent and can be determined from Figure 2.4 below. 

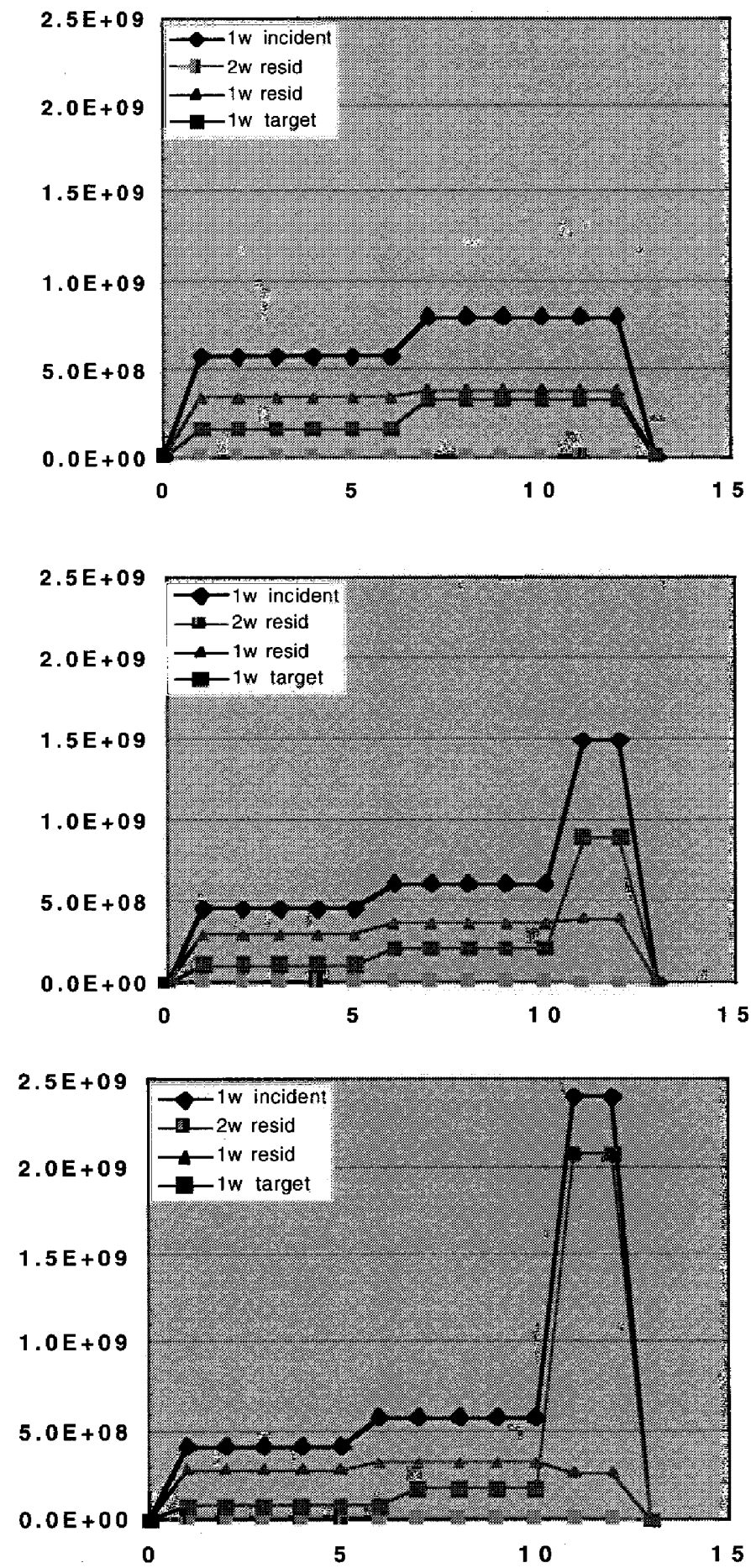

Figure 4.2 The conversion of first harmonic to the second and third harmonics for KDP and $\mathrm{KD}^{*} \mathrm{P}$ results are displayed. 
Examination of the unconverted light values shows the expected substantial unconverted light fluence. The predominantly first harmonic light strikes the far wall beam dump (steel louvers) after passing through best focus at approximately $42 \mathrm{~cm}$ beyond chamber center. From the focus lens at $740 \mathrm{~cm}$ to best focus is then $780 \mathrm{~cm}$ focal length allowing just $460 \mathrm{~cm}$ to reach the far wall's beam dump. The approximately 1600 $\mathrm{cm}^{2}$ available at the focus lens then shrinks to a $556 \mathrm{~cm}^{2}$ area. The resulting average fluence for the $900 \mathrm{~kJ}$ case is then $11.8 \mathrm{~J} / \mathrm{cm}^{2}$. Similar values were computed for $225 \mathrm{~kJ}$ and $450 \mathrm{~kJ}$ and is shown in Table 2.2.

\begin{tabular}{|c|c|c|c|}
\hline $\begin{array}{c}\text { Laser } \\
\text { Energy }(\mathrm{kJ})\end{array}$ & $\begin{array}{c}\text { \% Conversion } \\
\text { Efficiency }\end{array}$ & $\begin{array}{c}\mathrm{J} / \mathrm{cm}^{2} \text { at the Beam } \\
\text { Dump (average) }\end{array}$ & $\begin{array}{c}\text { Steel Ablated at } \\
\text { Beam Dump }\end{array}$ \\
\hline 225 & $37 \%$ & 13.8 & $34 \mathrm{mg}$ \\
\hline 450 & $39.6 \%$ & 12.7 & $67 \mathrm{mg}$ \\
\hline 900 & $53 \%$ & 11.8 & $82 \mathrm{mg}$ \\
\hline
\end{tabular}

Table 4.2 Shows the impact of the unconverted light incident for each laser energy considered.

The steel ablated values shown in Table 4.2 were calculated using the empirical relation shown in Figure 2.7 that was developed using data taken here at LLNL by Burnham et al. The number assume a $90 \%$ fraction of material captured at the stainless steel louvers. 


\subsection{X-ray Environment}

Calculations indicate that the $\mathrm{CH}$ wall seems to reduce the total $\mathrm{x}$-ray emission from the wall about $50 \%$ from the case of a bare gold wall. Additionally, the total net efficiency of $\mathrm{x}$-ray production appears to scale somewhat linearly with reduced laser energy. The table below (Table 4.1) gives approximate values for the amount of x-rays emitted from the various parts of the hohlraum. The pulse durations are expected to be $\sim 10 \mathrm{~ns}$ (LEH) to $\sim 100 \mathrm{~ns}$ (wall) with the diagnostic hole falling in between $(\sim 50 \mathrm{~ns})$. The spectrum from the LEH will be the hardest, characteristic of the hohlraum temperature, about $\sim 275 \mathrm{eV}$ BB. The spectra from the wall and diagnostic holes will be $\sim 50 \mathrm{eV}$.

\begin{tabular}{|l|c|c|c|}
\hline Laser Energy (kJ) & $\mathbf{2 2 5}$ & $\mathbf{4 5 0}$ & $\mathbf{9 0 0}$ \\
\hline X-ray Energy Total & 22.5 & 112.5 & 360 \\
\hline X-rays LEH & 15.8 & 67.5 & 180 \\
\hline X-rays Diagnostic Hole & 4.5 & 28.1 & 108 \\
\hline X-rays Wall & 2.2 & 16.9 & 72 \\
\hline
\end{tabular}

Table 4.3 Calculated x-ray energies for the three different laser energies.

Since there is a Lambertian distribution of radiation from both the LOSs and the diagnostic holes, but a radial distribution from the wall, estimates of the $x$-ray fluences can be made on the relevant nearby surfaces. These are shown in table 4.3. These are used to calculate $x$-ray fluences on the different facing components in the three tables below. We then calculated the ablated mass and the sum of the ablated mass for all components. These masses are compared to the other sources in table 4.4. For the target mass, we did not include $\mathrm{CH}$ material as it is expected to be pumped out of the chamber. The table shows that mass from the beam dumps is the major source.

225 kJ Laser Shot

\begin{tabular}{|c|c|c|c|c|c|}
\hline Surface & $\begin{array}{c}\text { Wall X-ray } \\
\text { Fluence }\end{array}$ & $\begin{array}{l}\text { Diag. Hole } X- \\
\text { ray Fluence }\end{array}$ & $\begin{array}{l}\text { LEH X-ray } \\
\text { Fluence }\end{array}$ & $\begin{array}{l}\text { Total X-ray } \\
\text { Fluence }\end{array}$ & $\begin{array}{c}\text { Debris mass } \\
(\mathrm{mg})\end{array}$ \\
\hline $\begin{array}{c}\text { Ta Pinhole @ } \\
5 \mathrm{~cm}\end{array}$ & 7.0 & 29 & 0 & 36 & 0.03 \\
\hline $\begin{array}{c}\text { Target Positioner } \\
\text { Plate } @ 10 \mathrm{~cm}\end{array}$ & $\overline{1.8}$ & 3.3 & 12 & 17 & 1.6 \\
\hline $\begin{array}{c}\text { Be shield @50 cm } \\
{\left[\text { SXI - } 161^{\circ}\right]}\end{array}$ & 0.07 & 0 & 0.14 & 0.21 & - \\
\hline $\begin{array}{l}\text { Be shield @45 cm } \\
\text { [gated detector] }\end{array}$ & 0.09 & 0.35 & 0 & $\overline{0.44}$ & - \\
\hline $\begin{array}{c}\text { Be shield } @ 50 \mathrm{~cm} \\
\text { [DMIX - 36 ?] }\end{array}$ & 0.07 & 0 & 0.14 & 0.21 & - \\
\hline $\begin{array}{c}\text { Be shield @50 cm } \\
{\left[S X I-18^{\circ}\right]}\end{array}$ & 0.07 & 0 & 0.14 & 0.21 & - \\
\hline & & & & & \\
\hline Total & & & & & 1.63 \\
\hline
\end{tabular}


$450 \mathrm{~kJ}$ Laser Shot

\begin{tabular}{|c|c|c|c|c|c|}
\hline Surface & $\begin{array}{l}\text { Wall X-ray } \\
\text { Fluence }\end{array}$ & $\begin{array}{c}\text { Diagnostic } \\
\text { Hole X-ray } \\
\text { Fluence }\end{array}$ & $\begin{array}{l}\text { LEH X-ray } \\
\text { Fluence }\end{array}$ & $\begin{array}{l}\text { Total X-ray } \\
\text { Fluence }\end{array}$ & $\begin{array}{l}\text { Debris Mass } \\
\text { (mg) }\end{array}$ \\
\hline $\begin{array}{c}\text { Ta Pinhole @ } \\
5 \mathrm{~cm}\end{array}$ & 54 & 179 & 0 & 233 & 0.06 \\
\hline $\begin{array}{c}\text { Target Positioner } \\
\text { Plate } @ 10 \mathrm{~cm}\end{array}$ & 13 & 21 & 49 & 84 & 3.2 \\
\hline $\begin{array}{c}\text { Be shield @50 cm } \\
{\left[S X I-161^{\circ}\right]}\end{array}$ & 0.54 & 0 & $\overline{0.6}$ & 1.14 & 0.1 \\
\hline $\begin{array}{c}\text { Be shield @45 } \mathrm{cm} \\
\text { [gated detector] }\end{array}$ & 0.7 & 2.2 & 0 & 2.9 & 0.5 \\
\hline $\begin{array}{c}\text { Be shield @50 cm } \\
\text { [DMIX - 36?] }\end{array}$ & 0.54 & 0 & $\overline{0.6}$ & 1.14 & 0.1 \\
\hline $\begin{array}{c}\text { Be shield @50 cm } \\
\text { [SXI - 18 }\end{array}$ & 0.54 & 0 & 0.6 & 1.14 & 0.1 \\
\hline Total & & & & & 4.06 \\
\hline
\end{tabular}

$900 \mathrm{~kJ}$ Laser Shot

\begin{tabular}{|c|c|c|c|c|c|}
\hline Surface & $\begin{array}{c}\text { Wall X-ray } \\
\text { Fluence }\end{array}$ & $\begin{array}{c}\text { Diagnostic } \\
\text { Hole X-ray } \\
\text { Fluence }\end{array}$ & $\begin{array}{c}\text { LEH X-ray } \\
\text { Fluence }\end{array}$ & $\begin{array}{c}\text { Total X-ray } \\
\text { Fluence }\end{array}$ & $\begin{array}{c}\text { Debris Mass } \\
\text { (mg) }\end{array}$ \\
\hline $\begin{array}{c}\text { Ta Pinhole @ } \\
5 \mathrm{~cm}\end{array}$ & 229 & 688 & 0 & 917 & 0.09 \\
\hline $\begin{array}{c}\text { Target Positioner } \\
\text { Plate @10 cm }\end{array}$ & 57 & 79 & 132 & 268 & 4.8 \\
\hline $\begin{array}{c}\text { Be shield @50 cm } \\
{\left[\text { SXI - } 161^{\circ}\right]}\end{array}$ & 2.3 & 0 & 1.61 & 3.9 & 0.8 \\
\hline $\begin{array}{c}\text { Be shield @45 cm } \\
\text { [gated detector] }\end{array}$ & 2.8 & 8.5 & 0 & 11.3 & 1.1 \\
\hline $\begin{array}{c}\text { Be shield @50 cm } \\
{\left[\text { DMIX - 36 } 6^{\circ}\right]}\end{array}$ & 2.3 & 0 & 1.61 & 3.9 & 0.8 \\
\hline $\begin{array}{c}\text { Be shield @50 cm } \\
{\left[\text { SXI - 18 }{ }^{\circ} \text { ] }\right.}\end{array}$ & 2.3 & 0 & 1.61 & 3.9 & 0.8 \\
\hline & & & & & \\
\hline Total & & & & & 8.39 \\
\hline
\end{tabular}

\begin{tabular}{|c|c|c|c|c|}
\hline $\begin{array}{c}\text { Laser } \\
\text { Energy }(\mathrm{kJ})\end{array}$ & $\begin{array}{c}\text { Target not } \\
\text { counting CH }\end{array}$ & Beam Dumps & Surfaces & Total \\
\hline 225 & 22.5 & 34 & 1.6 & 58.1 \\
\hline 450 & 22.5 & 67 & 4.1 & 93.6 \\
\hline 900 & 22.5 & 82 & 8.4 & 112.9 \\
\hline
\end{tabular}

Table 4.4 Total debris mass expected from the three sources. 


\subsection{Shrapnel and Debris from Ta Pinhole Array Due to X-Ray Loading}

LASNEX (in its one-dimensional mode) is used to compute the effects of a $50 \mathrm{eV}$ blackbody $\mathrm{x}$-ray source (with a pulse duration of $20 \mathrm{~ns}$ ) on the target plate at three different fluences $\left(90,470\right.$, and $\left.1110 \mathrm{~J} / \mathrm{cm}^{2}\right)$. We give results for the intermediate 470 $\mathrm{J} / \mathrm{cm}^{2}$ case in this report. The total energy (internal plus kinetic) given by the LASNEX run at the end of the pulse duration is used to initialize the 2D free-Lagrangian code L2D. The latter carries on the hydrodynamic plate response to an equivalent energy deposition that simulates the radiation transport physics of LASNEX. L2D computes the 2D response of side-view pinhole plate shown in Fig. 2.1, and handles severe cell distortion of the plate response. From the L2D computations, the mass per circumferential length as a function of polar angle in the plane through the hohlraum normal to the tantalum plate is computed.

The L2D computations show the tantalum plate facing the hohlraum with vapor blowoff, followed by liquid, followed by solid material with two spalled regions. The overall response with vapor is shown in Figs. 4.1 and 4.2 after $137 \mathrm{~ns}$.

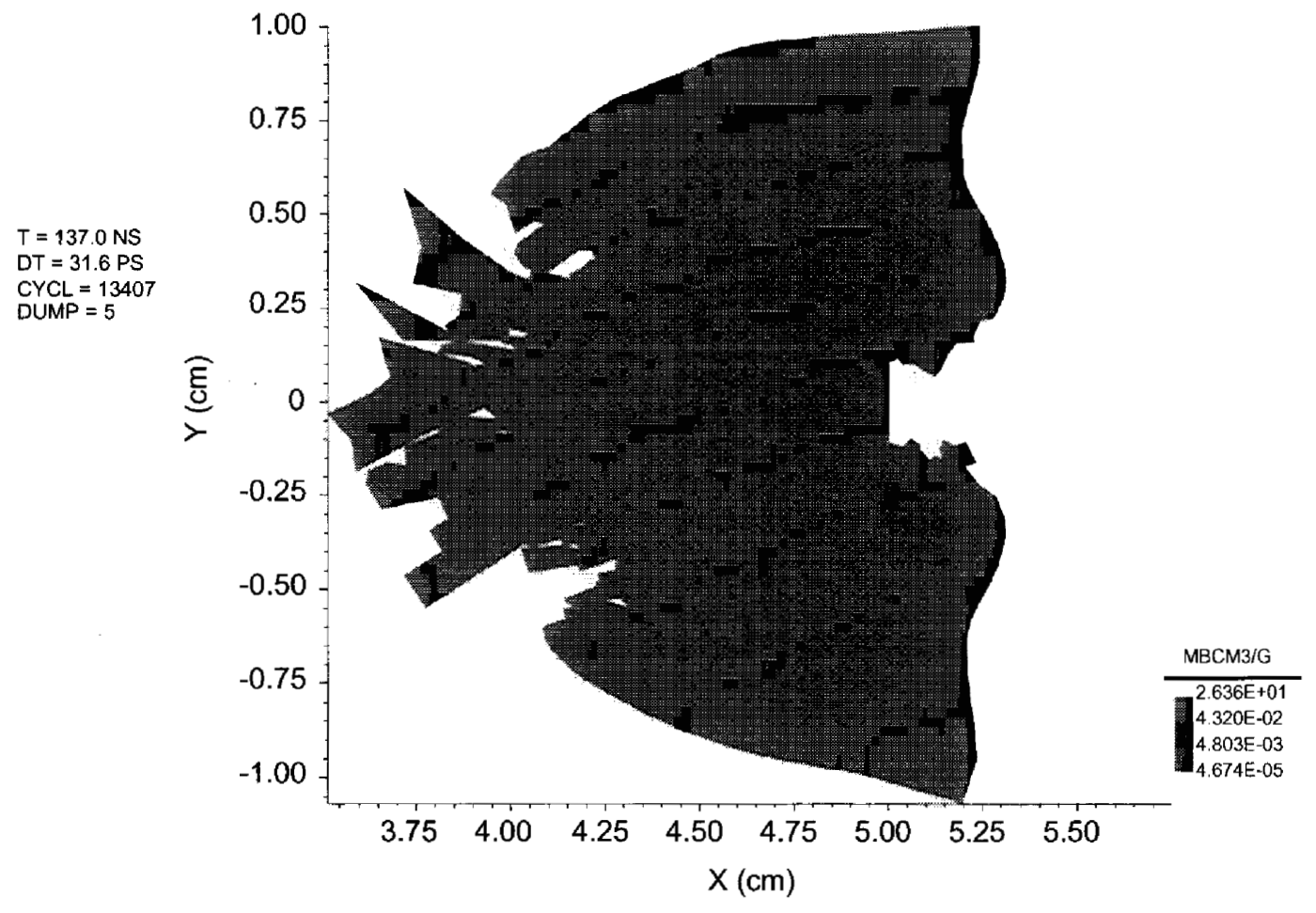

26-Sep-00 10:44:00 $470 \mathrm{~J}^{\mathrm{C}} \mathrm{CM}^{\wedge} 2$, TANTALUM

Figure 4.1 L2D blowoff from tantalum plate showing vapor. 


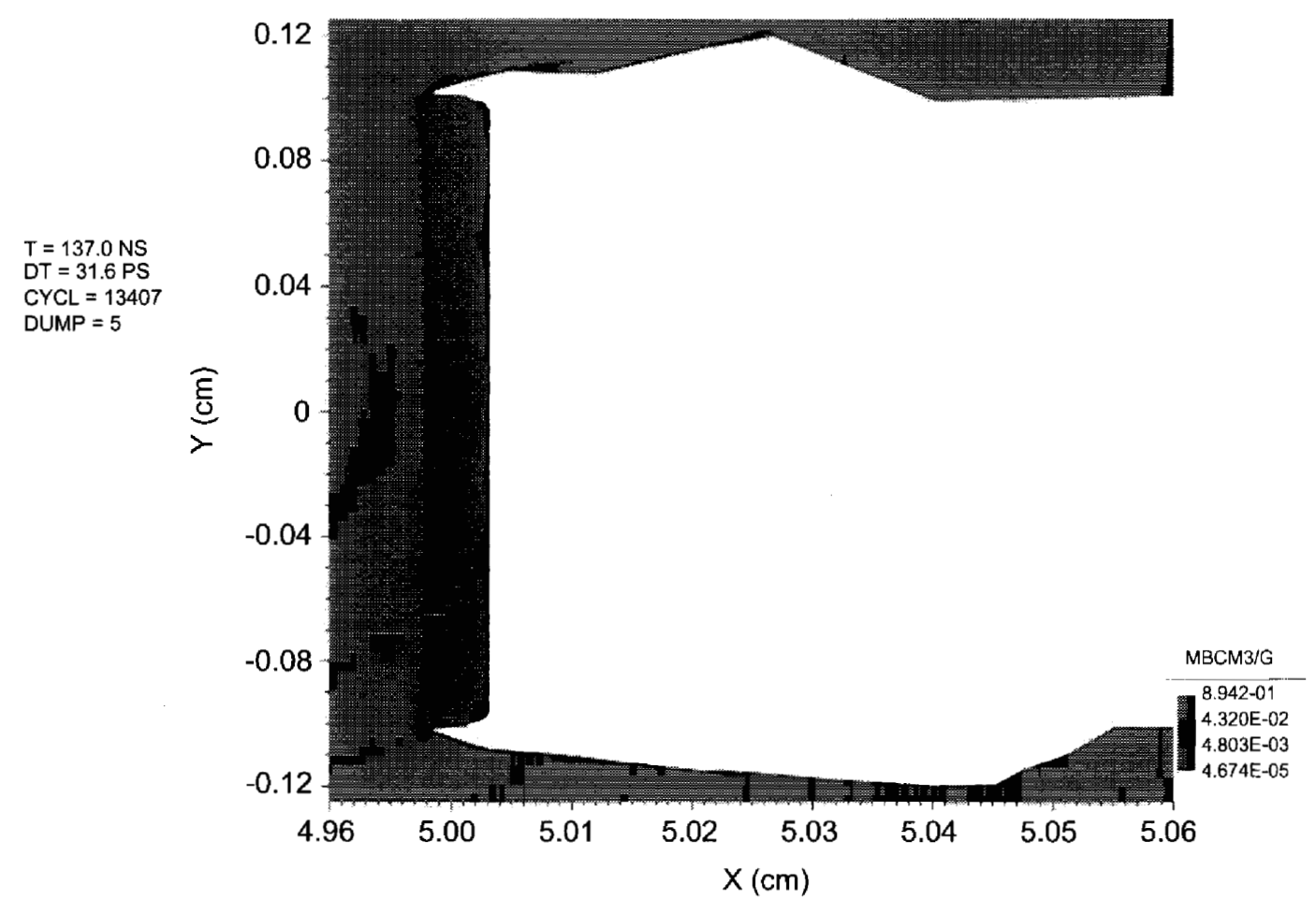

Figure 4.2 L2D blowoff from tantalum plate showing liquid and solid regions.

The separation of phases is shown in the two figures: The blue is solid, green is liquid (between melt and vapor sublimation energies), and the red is vapor/gas. The vapor blowoff expands in all directions and drags the melt toward the wall, mostly behind the tantalum plate.

The total masses of the various material states is given in Table 4.1 below.

\begin{tabular}{|l|l|}
\hline \multicolumn{1}{|c|}{ Material State } & \multicolumn{1}{c|}{ Mass (g) } \\
\hline Solid & $3.744 \mathrm{E}-3$ \\
\hline Fractured Solid & $1.387 \mathrm{E}-3$ \\
\hline Liquid & $1.30 \mathrm{E}-4$ \\
\hline Vapor & $6.8 \mathrm{E}-5$ \\
\hline \multicolumn{1}{|c|}{ Total mass $=$} & $5.329 \mathrm{E}-3$ \\
\hline
\end{tabular}

Table 4.1 Mass conservation for the L2D computation.

The density of the tantalum plate at $\pm 90 \%$ from the midline (i.e., $\pm 0.9 \mathrm{~mm}$ ), and at the midline, all referenced to the Lagrangian position, is shown in Fig. 4.3. Variations in responses at each end indicate variations that occur in L2D because there is considerable 
cell rezoning and the computations are performed in an unsymmetrical way with respect to the midpoint. The density indicates the solid and spalled (density of about 6 $\mathrm{g} / \mathrm{cm}^{3}$ ) regions that account for most of the target material, and the hot front material that transitions to liquid and vapor. The spall material is moving at slightly higher velocities than the solid plate as shown in Fig. 4.3. The vapor and liquid regions are moving significantly faster than the solid material. The solid material including the spalled region is moving primarily in the x-direction, i.e., towards the waist of the NIF chamber. This can be seen by the small velocities in the y-direction shown in Fig. 4.4. This means that only a small fraction of the pinhole array shrapnel would reach any of the debris shields. We discuss this issues in more detail below.

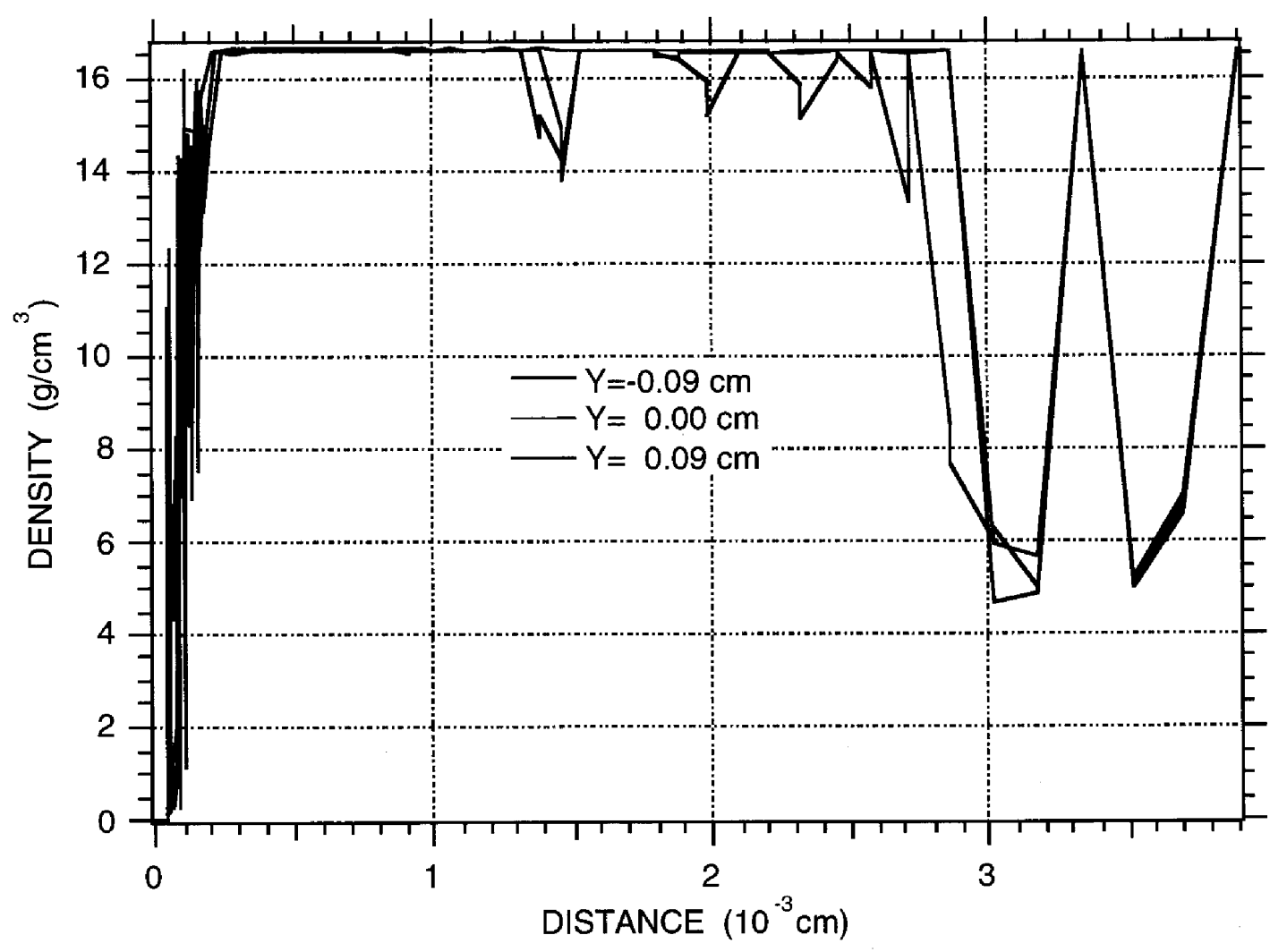

Figure 4.3 Density through the Ta plate showing regions of spall on back side. 


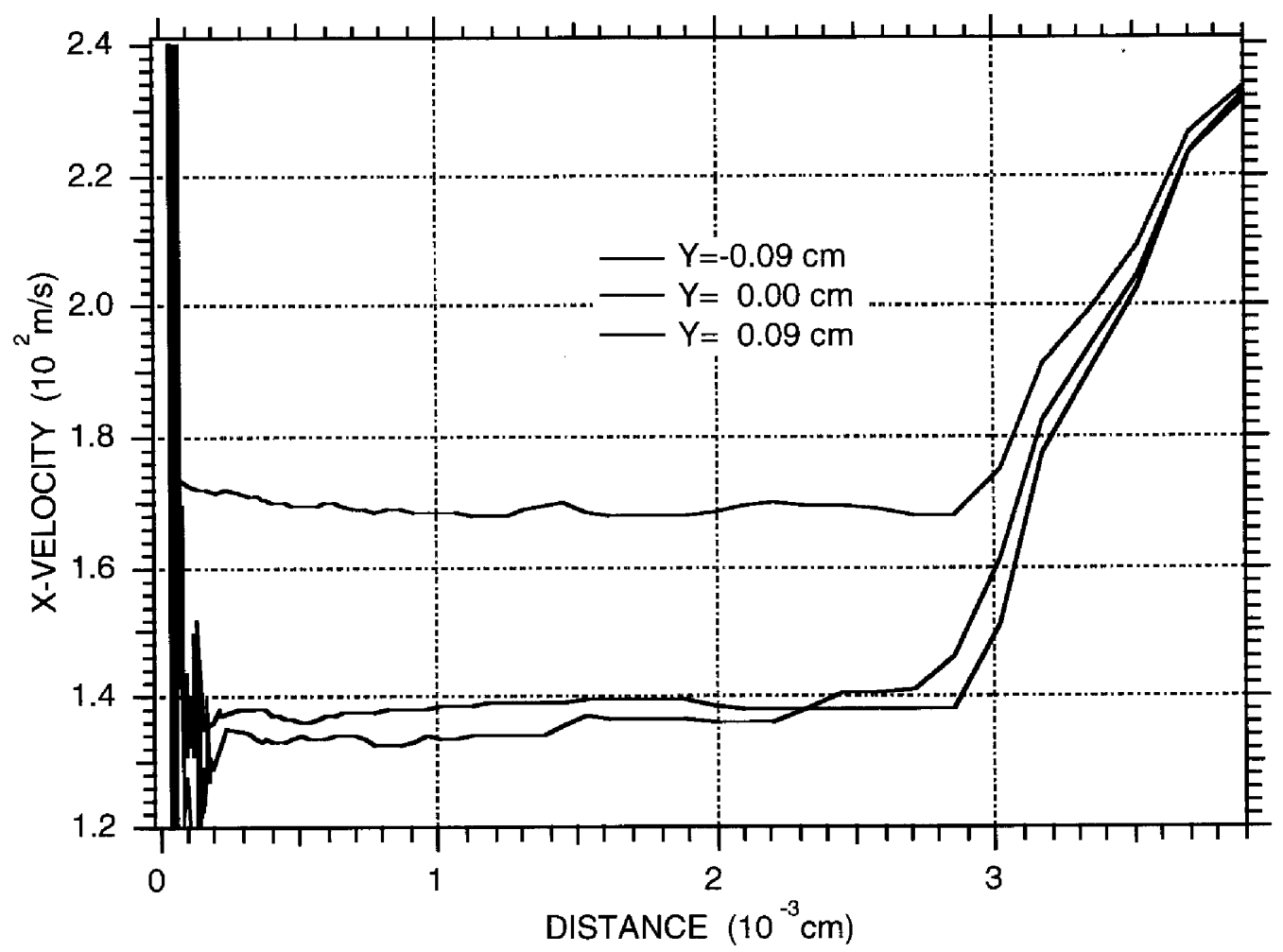

Figure 4.4 The $x$-velocity through the Ta plate showing the spall region with slightly higher velocities and the liquid and vapor with higher velocities.

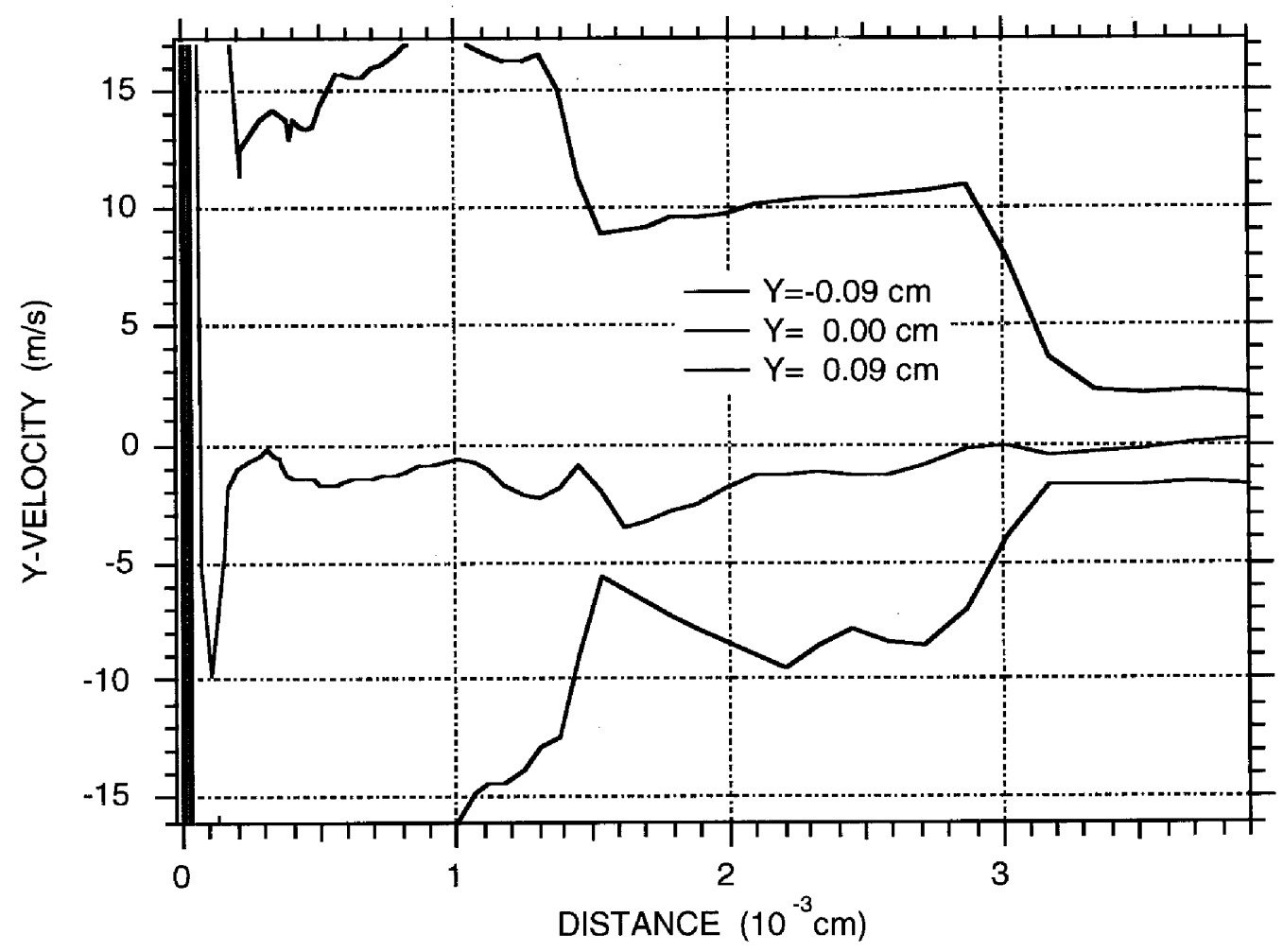

Figure 4.4 The y-velocity through the Ta plate is much less than the x-velocity. 
Plots of mass, momentum, and average particle size are given in Figs. 4.5, 4.6, and 4.7, respectively. The previous discussion describes our assumptions. The formula used for determining average particle size for the liquid is as follows:

$$
S_{\text {avg }}=3.6\left(\gamma / \rho \varepsilon^{\circ 2}\right)^{1 / 3}
$$

where $\gamma$ is the surface energy ( 3650 dyne/cm for tantalum), $\rho$ is the density, $\varepsilon^{\circ}$ is the maximum strain rate and the average particle size for the assumed plasticallydeforming solid is:

$$
\mathrm{S}_{\mathrm{avg}}=0.333(\mathrm{Y} / \rho)^{1 / 2} / \varepsilon^{\circ}
$$

where $\mathrm{Y}$ is the yield strength = (typical average value over energy range of 5E9 dyne $\left./ \mathrm{cm}^{2}\right), \rho$ is the density and $\varepsilon^{\circ}$ is the maximum strain rate. This formula for the solid is our best estimate based on the Grady-Curran results.

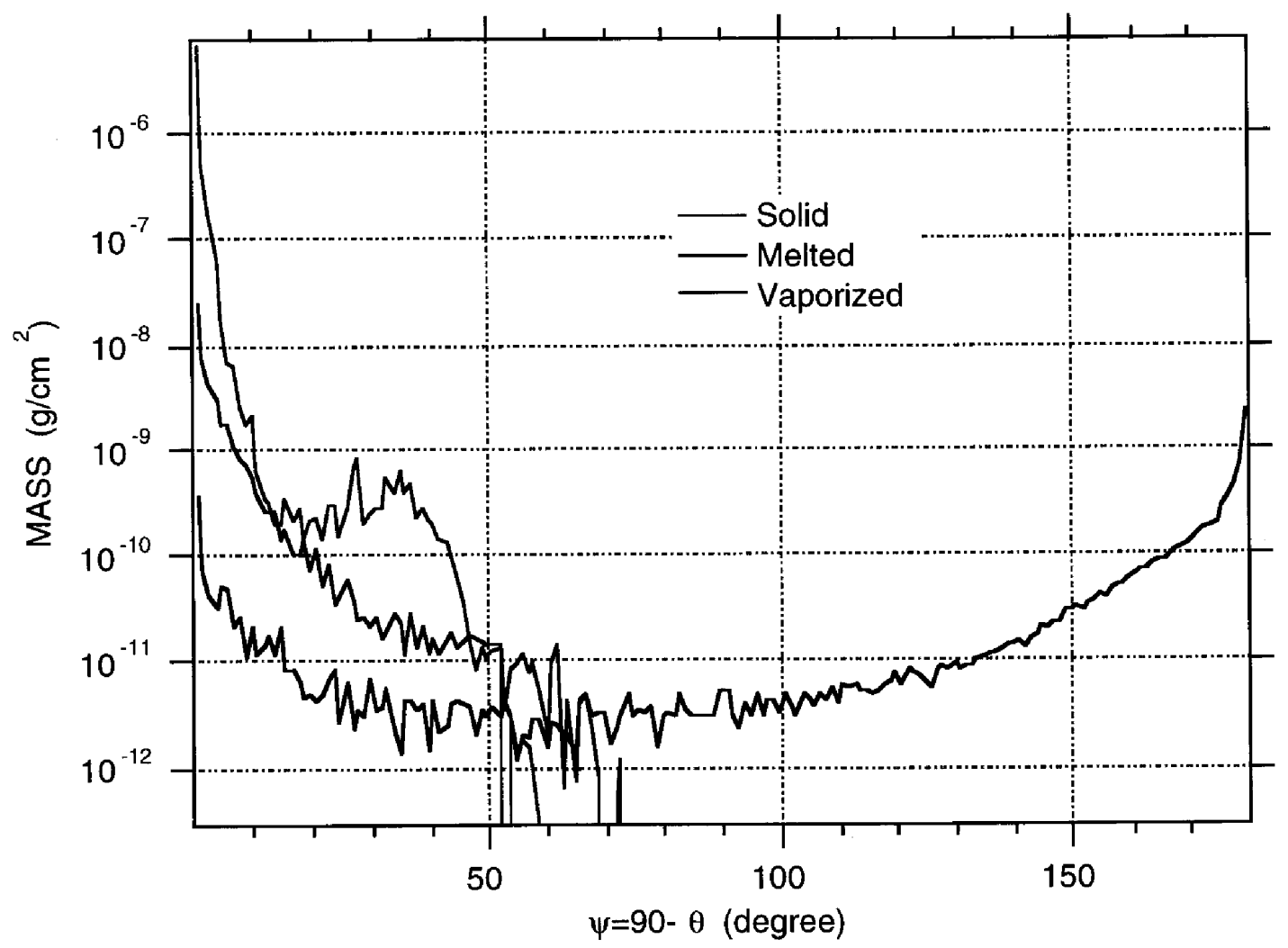

Figure 4.5 Mass distribution around target chamber $(5 \mathrm{~m})$ about an axis passing through target center and the center of the pinhole array. 


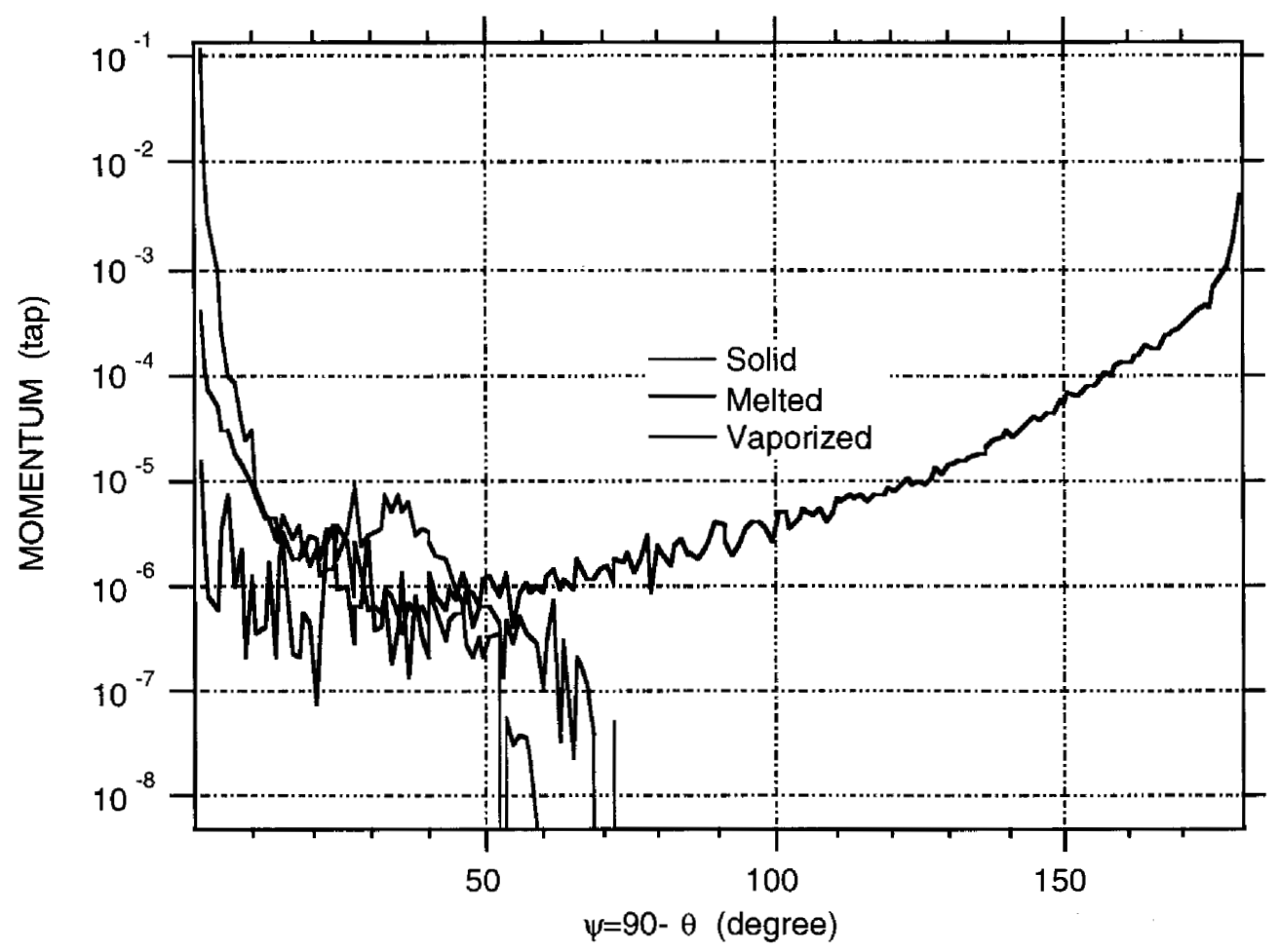

Figure 4.6 Momentum distribution around target chamber.

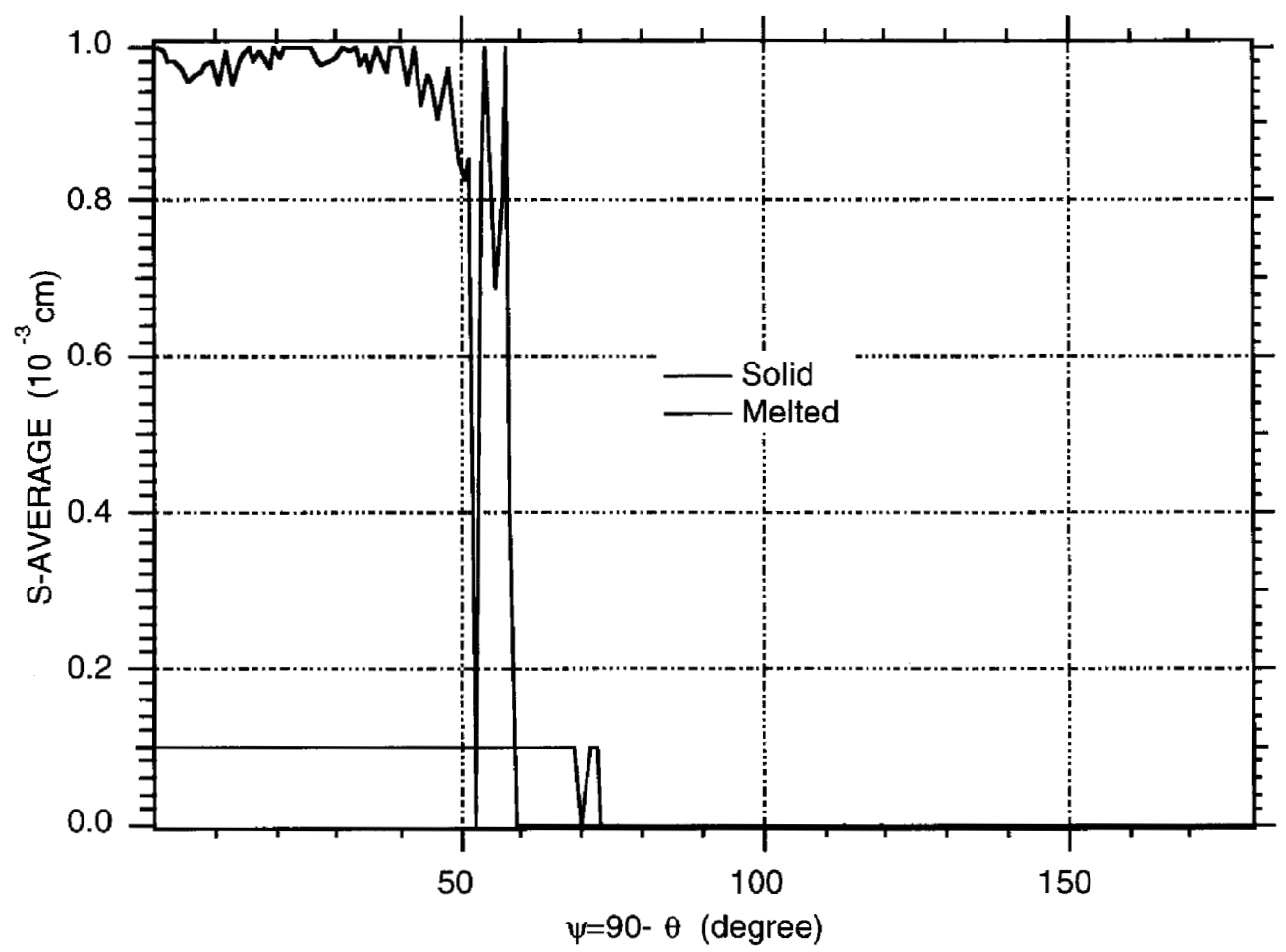

Figure 4.7 Average particle size around target chamber. 
Most of the plate mass remains intact and moves radially outward at the chamber waist, with some spalled solid spreading out at small angles. The liquid with about one order of magnitude less mass is also confined to small angles, and is blown there by the confining vapor blowoff at the front of the plate. The average size of the solid spalled material is of order $10 \mu \mathrm{m}$ and the average size of the liquid droplets is calculated to be of order $1 \mu \mathrm{m}$. The 50 degree set of debris shields that are on the side of the chamber where the pinhole array is located have some small exposure to shrapnel from the pinhole array. To estimate this shrapnel impact, we look at angles around 40 degrees in Figs. $4.5-4.7$. From Fig. 4.5, the mass per unit area at $5 \mathrm{~m}$ around 40 degrees is of order $10^{-10} \mathrm{~g} / \mathrm{cm}^{2}$ for solid fragments and of order $10^{-11} \mathrm{~g} / \mathrm{cm}^{2}$ for liquid droplets. The momentum is of order $2 \times 10^{-6}$ taps for the solid fragments and of order $10^{-6}$ taps for the liquid droplets. This corresponds to average velocities of order 200 and $1000 \mathrm{~m} / \mathrm{s}$ for solid and liquid fragments, respectively. To obtain a number density of fragments at the debris shields in question, we adjust the mass per unit area in going out to $7 \mathrm{~m}$ from the value given at the chamber wall at $5 \mathrm{~m}$ and use the average size of the fragments. For solid fragments, we have $5 \times 10^{-11} \mathrm{~g} / \mathrm{cm}^{2}$ with an average size of $10 \mu \mathrm{m}$. For liquid droplets, we have $5 \times 10^{-12} \mathrm{~g} / \mathrm{cm}^{2}$ with an average size of $1 \mu \mathrm{m}$. Using a density of 16.7 $\mathrm{g} / \mathrm{cm}^{3}$ for both liquid and solid fragments, we an average number of fragments per unit area to be of order have $5 \times 10^{-3}$ and $5 \times 10^{-1}$ fragments $/ \mathrm{cm}^{2}$ for solid and liquid fragments, respectively. The larger number of liquid fragments is due to their smaller size. Using the size, density, and velocity of the fragments in the expression for crater depth given in section 2.2.1, we obtain depth of 35 and $25 \mu \mathrm{m}$ for solid and liquid fragments, respectively. Assuming that the diameter of the craters is twice the depth, we calculate the fraction of area covered by craters to be $2 \times 10^{-7}$ and $1 \times 10^{-5}$ for solid and liquid induced craters, respectively. After 2 months of operation, 120 shots, the area of craters is only of order $0.1 \%$.

\subsection{Conclusions and Future Work}

We have presented a methodology that allows one to assess the debris-shield impact of experimental designs planned for NIF. We have applied this methodology to one set of experiments and have determined that the impact associated with the debris is modest and is within the guidelines. The impact of this particular design associated with shrapnel is very low as was expected. We are in the process of giving initial assessments to other planned designs. Significant impacts are expect both in the area of debris and shrapnel for some of these designs. In the area of modeling, there are three major aspects that we want to develop. First, would like to model the late time properties of hohlraums with codes that can better treat the shear follow. One potential code is HYDRA that uses an ALE hydro approach. Second, we would like to model 3D object, e.g., a diagnostic window in a hohlraum as in the experimental design discussed in this report. Finally, we have a longer term goal of a single code that self-consistently all steps from laser absorption to debris/shrapnel production. 


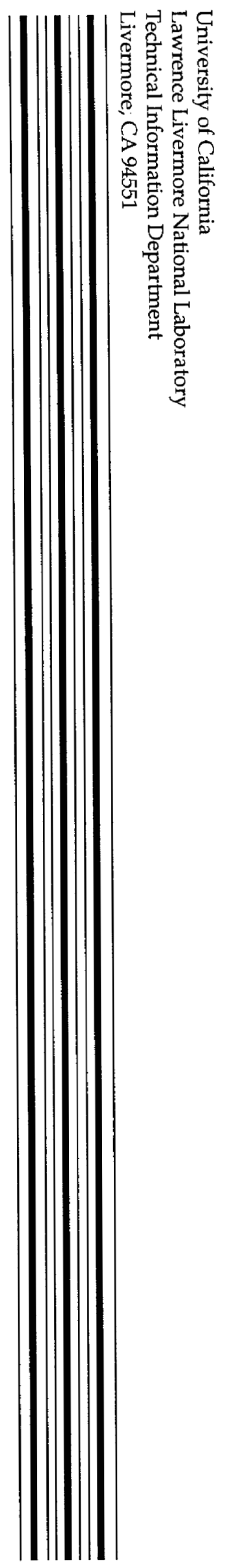

